\title{
Crystalline Swelling Process of Mg-Exchanged Montmorillonite: Effect of External Environmental Solicitation
}

\author{
Marwa Ammar and Walid Oueslati \\ UR13ES46 Physique des Matériaux Lamellaires et Nano-Matériaux Hybrides (PMLNMH), Faculté des Sciences de Bizerte, \\ 7021 Zarzouna, Tunisia \\ Correspondence should be addressed to Walid Oueslati; walidoueslati@ymail.com
}

Received 8 May 2018; Revised 9 August 2018; Accepted 9 September 2018; Published 16 October 2018

Academic Editor: Dingwen Zhang

Copyright (c) 2018 Marwa Ammar and Walid Oueslati. This is an open access article distributed under the Creative Commons Attribution License, which permits unrestricted use, distribution, and reproduction in any medium, provided the original work is properly cited.

\begin{abstract}
This work reports characterization of the possible effects that might distress the hydration properties of Mg-exchanged lowcharge montmorillonite (SWy-2) when it undergoes external environmental solicitation. This perturbation was created by an alteration of relative humidity rates (i.e., $\mathrm{RH} \%$ ) over two hydration-dehydration cycles with different sequence orientations. Structural characterization is mainly based on the X-ray diffraction (XRD) profile-modeling approach achieved by comparing the "in situ" obtained experimental 001 reflections with other ones calculated from theoretical models. This method allows assessing the evolution of the interlayer water retention mechanism and the progress of diverse hydration state's contributions versus external strain. Obtained results prove that the hydration behavior of the studied materials is strongly dependent on the $\mathrm{RH}$ sequence orientation which varied over cycles. The interlayer organization of Mg-exchanged montmorillonite (i.e., SWy-2$\mathrm{Mg}$ ) is characterized by a heterogeneous hydration behavior, which is systematically observed at different stages of both cycles. By comparing the interlayer water process evolution of Mg-exchanged montmorillonite with the observed SWy-2-Ni sample hydration behaviors, a same hysteresis thickness characterized by obvious fluctuations of interlayer water molecule abundances is observed. Nevertheless, in the case of $\mathrm{Hg}$ and Ba-saturated montmorillonite, the retention water process versus the applied cycles was steadier comparing with $\mathrm{Mg}$ ions.
\end{abstract}

\section{Introduction}

Smectites are swelling clay minerals that belong to the family of the phyllosilicates $2: 1$, which naturally occur in both terrestrial and marine environments [1] where they often represent the most effective components. In fact, by dint of its significant intrinsic physical and chemical properties, mainly the high specific surface areas (up to $760 \mathrm{~m}^{2} \cdot \mathrm{g}^{-1}$ ), the cation-exchange capacities as well as the high sorption efficiency of cations, and its strong mechanical stability [2], these materials were used in many extensive exploitation. Indeed, it plays an important role in many geological processes, the phenomena of the petroleum migration, greenhouse gas sequestration, oilfield [3], and in engineering. Moreover, for last decades, the smectites were widely used as crucial components for elaboration of natural barriers to isolate the hazardous wastes and for the removal of heavy metal cations from various effluents of industrial and wastewater treatment [4-12] and also proposed as geotechnical barriers in many nuclear waste disposal concepts in order to retard the potential transport of radionuclides towards the biosphere [13-15].

Notwithstanding the diverse beneficial effects of smectites, the hydration behavior of these mineral is very sensitive to the change of the environmental surrounding conditions (i.e., temperature, pressure, and $\mathrm{RH}$ ), which may influence the stability of the clay microstructure therefore the stability of the geotechnical barrier. Hence, the well understanding of swelling smectites properties (the hydration and the dehydration mechanism) is of paramount importance for many natural processes and for such applications.

The water-metal-smectites system was the subject of diverse studies, and it was extensively studied at different scales using several characterization methods [16-26]. At 
nanometer scale, the swelling process corresponds to the presence of hydrated chemical species on the interlayer space. This process depends on several factors including composition such as the layer charge amount, the charge location and distribution [27-30], the interlayer cation type, the interlayer cation valence, and the hydration energy [31] and also on the environment conditions such as the relative humidity, temperature, and $\mathrm{H}_{2} \mathrm{O}$ pressure [32-37]. The pioneering studies focusing the crystalline swelling was performed using X-ray diffraction technique. By following the evolution of $d_{001}$ basal-spacing value, different hydration states were defined with the insertion of $0,1,2$, or 3 planes of $\mathrm{H}_{2} \mathrm{O}$ molecules in the interlamellar spaces leading to growth of the spacing values as function of $\mathrm{RH} \%$ [28,38-40].

Furthermore, the development of the XRD profilemodeling procedures and the methodology proposed by [41] allows the characterization of the structural modifications that occur during smectite swelling process. In addition, by using the XRD modeling approach, the quantification of hydration heterogeneity becomes easier especially when different layer hydration state types coexist in the same smectite structure. Several studies used this modeling approach tools to study the hydration properties of different smectite sample types and demonstrate systematic hydration heterogeneity whatever the interlayer cation, the $\mathrm{RH} \%$, the amount, the layer charge location, and the surrounding temperature [40,42-46].

According to this method, the present work focuses the damage that may affect the structural properties of the host materials and the hydrous behavior of an Mg-saturated smectite (i.e., montmorillonite: SWy-2) when it was submitted to a continuous variation of an environmental surroundings condition (i.e, variable $\mathrm{RH} \%$ ). This environmental solicitation is performed by varying "in situ" the $\mathrm{RH} \%$ in reverse sequence orientation upon two hydration/dehydration cycles. Upon the applied cycles and under controlled atmosphere, a complex progress of the interlamellar space configuration of SWy-2-Mg sample is followed and quantified. After that the obtained results are compared with the earlier studies related to the same studied specimen which is saturated with other bivalent cations $(\mathrm{Hg}, \mathrm{Ba}$, and $\mathrm{Ni}$ ) and submitted to the same climatic changes over the hydration-dehydration cycles for the purpose of discriminating the effect of the ionic potential on the crystalline swelling.

\section{Materials and Methods}

2.1. Host Materials. A dioctahedral smectite SWy-2 originated from bentonites of Wyoming (USA) is selected for the present study. Clay fraction is supplied by the Source Clay Minerals Repository Collection of the Clay Minerals Society and characterized by the following half-cell structural formula [47]:

The cation-exchange capacity (CEC) of this smectite is $101 \mathrm{meq} / 100 \mathrm{~g}$ where the charge deficit is majority resulting from cationic substitutions in the octahedral sheet and extremely limited tetrahedral ones.

2.2. Sample Treatments. To saturate all exchangeable sites by homoionic cations $\left(\mathrm{Na}^{+}\right)$and to guarantee better colloidal dispersion, a pretreatment of the host material is carried out in order to prepare a $\mathrm{Na}$-rich montmorillonite suspension. This aims is based on a classical protocol of an exchange process [48] which consists of dispersing $\sim 20 \mathrm{~g}$ of solid in $\sim 200 \mathrm{ml}$ of $\mathrm{NaCl}$ solution (1 M) and stirring mechanically for $24 \mathrm{~h}$. A SIGMA laboratory centrifuge is used for the separation of the solid fraction at $4000 \mathrm{rpm}$ speed. These steps were repeated five times to ensure saturation of all exchangeable sites by $\mathrm{Na}^{+}$cations. Excess chloride was removed by washing with distilled water five times, and the separation of the solid-liquid was performed by centrifugation at $8000 \mathrm{rpm}$ speed. The same ionic exchange procedure was followed to prepare $\mathrm{Mg}$-rich montmorillonite suspension using $\mathrm{MgCl}_{2}$ solution (1M), and the final obtained clay suspension was labeled SWy-2-Mg.

Two oriented slides were prepared for the obtained samples (SWy-2-Mg) to be analyzed by XRD technique. For that the specimen suspension was deposed on a glass slide and then dried at room temperature for 24 hours to obtain an air-dried preparation [49].

2.3. "In Situ" XRD Analysis. The "in situ" XRD patterns produced by SWy-2-Mg sample are obtained upon two overturn hydration-dehydration cycles. These cycles were created by varying gradually the $\mathrm{RH} \%$ in reverse orientation with a $10 \%$ step. For that an Anton Paar TTK 450 chamber coupled with a D8 Advance Brüker installation (Cu-Ka radiation) equipped with solid-state detector and operating at $40 \mathrm{KV}$ and $30 \mathrm{~mA}$ was used. The reflection setting diffractometer installation is equipped with an Ansyco rhplus 2250 humidity control device used to vary manually the $\mathrm{RH} \%$. The hydration-dehydration cycle orientations were detailed in Figure 1 and can be resumed as follows.

Both applied cycles were performed in three successive processes starting from $40 \% \mathrm{RH}$, which coincides with the relative humidity value of the room condition $(297 \mathrm{~K}$ and $\sim 40 \% \mathrm{RH})$.

The first cycle is divided into three domains summarized as follows.

The first one (I) consists of a hydration process realized by increasing the $\mathrm{RH} \%$ from 40 to almost saturated condition $(80 \%)$ followed by a dehydration procedure (II) assured by the decrease of the RH\% towards extremely dry condition (10\%). Finally, a rehydration process (III) was performed to a second return to $40 \% \mathrm{RH}$ (Figure 1).

The sequential RH orientation was accomplished in an inverse way for the second cycle. Indeed, starting from $40 \%$ $\mathrm{RH}$, a dehydration process was performed decreasing the $\mathrm{RH} \%$ to $10 \%$, followed by a hydration procedure reaching $80 \% \mathrm{RH}$ and to finish with a second dehydration process by lessening the RH\% to $40 \%$ (Figure 1).

Over these applied cycles, experimental XRD patterns were registered, in situ, every $10 \%$ at the fixed relative humidity condition values where the usual scanning parameters were $0.04^{\circ} 2 \theta$ as step size and $6 s$ as counting time per step over the angular range $2-40^{\circ} 2 \theta$. In total, sixteen experimental patterns were recorded per cycle, and for all obtained 001 reflection, quantitative and quanlitative XRD analyses are performed. 


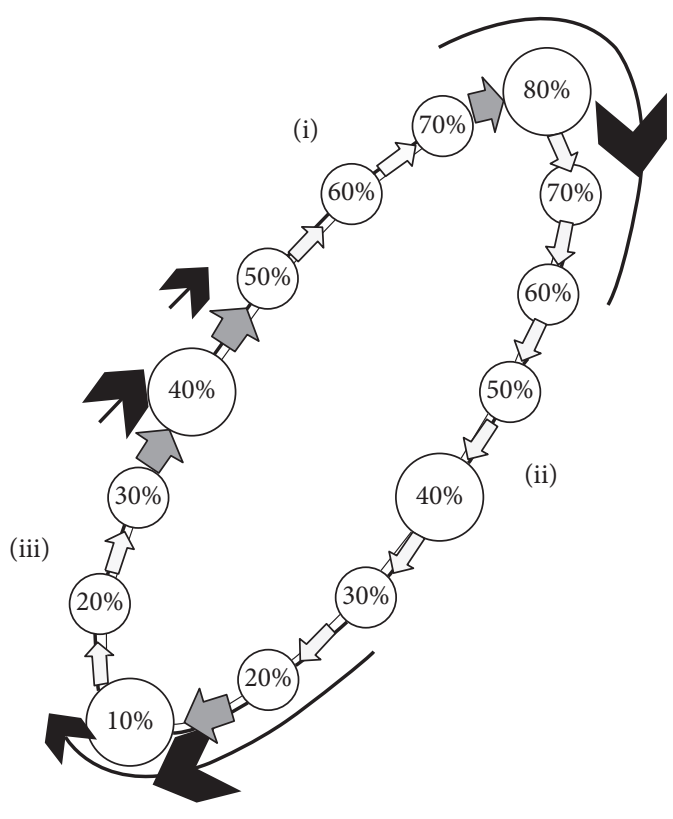

First cycle
(i) Hydration process
(ii) Dehydration process

(iii) Rehydration process

(a)

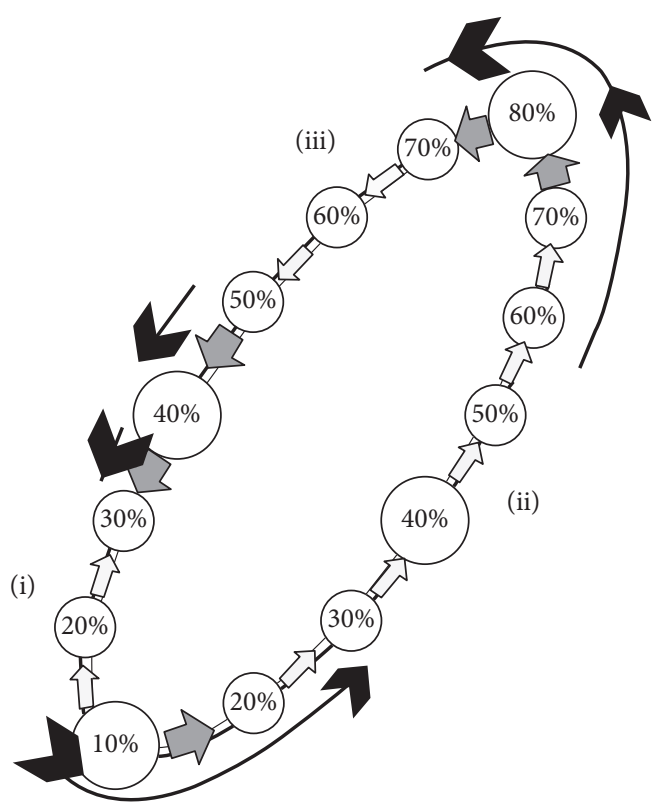

Second cycle

(i) Dehydration process

(ii) Hydration process

(iii) Second dehydration process

(b)

Figure 1: Sequence variation of the RH\% during different hydration-dehydration cycles.

2.3.1. Qualitative XRD Pattern Investigations. A primeval interpretation about the hydration states of the studied samples can be obtained from a qualitative XRD analysis of the experimental profile. This information was deduced through the $d_{001}$ basal-spacing values and a description of the 001 reflection profile geometry (pics symmetry and/or asymmetry). In addition, the correlation between the calculated parameters including the full width at half maximum intensity (FWHM) for the 001 reflections and $\xi$ parameters $[42,50]$ can supply information about the hydration character of the studied samples (homogenous or interstratified). Nevertheless, the qualitative examination cannot provide information about structural transformation related to the position and organization of $\mathrm{H}_{2} \mathrm{O}$ molecule and the exchangeable cations along the $\mathrm{c}^{*}$ axis. In addition, it is impossible to distinguish the nature and the relative contributions of different hydration phases at different $\mathrm{RH}$ values varied over the cycles. Thus, a quantitative evaluation of diverse changes which occurs within the smectite structure was required to accomplish the aims of the studies.

2.3.2. XRD Profile-Modeling Approach. The quantitative analysis is based on the XRD profile-modeling approach in order to propose theoretical structural models estimating, respectively, the gradual evolution of the interlamellar space content versus the hydration sequences, the nature of the different layer types coexisting within crystallites, and their proportion and their structural composition at different stages of both the applied cycles.

This method consists of adjusting the experimental XRD patterns (001 reflection) to theoretical ones where the calculated intensity is based on the algorithms developed by [41]. The theoretical matrix formalism was detailed by [41]. The used $\mathrm{Z}$ atomic coordinates of the interlayer space correspond to those proposed by [41]. The abundances of the different types of layers $\left(\mathrm{W}_{\mathrm{i}}\right)$, the mode of stacking of the different kinds of layers, and the mean number of layers per coherent scattering domain (CSD) [51] can be determined also through XRD profile-modeling approach. The layertype stacking is described by a set of junction probabilities $\left(P_{i j}\right)$ where the relationships between these probabilities and the abundances $W_{i}$ of the different types of layers were given by [41]. A detailed description of the fitting strategy was detailed in the work of $[37,40]$. Indeed, XRD patternmodeling was performed assuming the possible presence of different layer types. These different layer types correspond to the different hydration states commonly reported in smectites as a function of relative humidity. In the fitting process, we have introduced dehydrated layers (0W layers, layer thickness at 9.6-10.0 ̊), monohydrated layers with one plane of $\mathrm{H}_{2} \mathrm{O}$ molecules in the interlayer (1W layers at 11.5-13.0 $\AA$ ), bihydrated layers with two planes of $\mathrm{H}_{2} \mathrm{O}$ molecules in the interlayer ( $2 \mathrm{~W}$ layers at $13.9-15.8 \AA$ ), and trihydrated layers (3W layers at 18.0-18.5 $)$.

\section{Results}

\subsection{Quantifying Interlamellar Space Content during the First Cycle}

3.1.1. Qualitative XRD Analysis. All experimental XRD patterns produced by the SWy-2-Mg sample during the first 
cycle are presented in Figure 2 with the calculated profile, obtained using the corresponding contributions of the various mixed-layer structures (MLSs).

A qualitative investigation was performed providing preliminary information about the hydration property evolution. In fact, a homogenous hydration character is observed at the highest $\mathrm{RH}$ range extending between $70 \%$ (hydration process) $\leq \mathrm{RH} \leq 60 \%$ (dehydration process). This description is confirmed by the low value of the calculated FWHM, the $\xi$ parameter (Table 1) of the 001 reflection positions over the RH fields. On the contrary, a heterogeneous hydration behavior was deduced at the lowest $\mathrm{RH}$ range justified by the irrationality, for all measurable reflection positions, characterized by high $\xi$ parameter values (Table 1).

The gradual evolution of the $d_{001}$ basal-spacing values as function of RH\% (Figure 3(a)) shows a clear hysteresis between $40 \% \leq \mathrm{RH} \leq 10 \%$. For this $\mathrm{RH}$ range, the structure is dominated by an interstratified hydration behavior between $1 \mathrm{~W}$ and $2 \mathrm{~W}$ layer types. However, the variation of the $d_{001}$ spacing between 80 and $40 \% \mathrm{RH}$ tails the same roads which can be interpreted by a hydrous stability on the interlayer spaces.

\subsubsection{Theoretical Models and the Hydration Properties.} The structural parameters used to reproduce experimental patterns of SWy-2-Mg as a function of $\mathrm{RH} \%$ were regrouped in Table 2. Results derived from the quantitative XRD investigation demonstrate that the studied structure (i.e., SWy$2-\mathrm{Mg}$ ) changes, all over the cycle, with an interstratified hydration behavior. Indeed, all proposed models are described by a main structure composed by diverse hydration state contributions $(0 \mathrm{~W}, 1 \mathrm{~W}, 2 \mathrm{~W}$, and $3 \mathrm{~W})$ at different $\mathrm{RH}$ values (Figure 2).

These heterogeneous hydration behaviors can be explained by sequential transitions between different hydration states induced by the continuous variation of the RH\%. The evolution of different relative layer-type proportions as a function of the $\mathrm{RH} \%$ (Figure 4) shows a continuous diffusion of $\mathrm{H}_{2} \mathrm{O}$ molecules in the interlamellar spaces during the hydration process leading to progressive and continuous $1 \mathrm{~W} \rightarrow 2 \mathrm{~W}$ and $2 \mathrm{~W} \rightarrow 3 \mathrm{~W}$ transitions.

In fact, at the beginning of the cycle (40\% RH), the studied sample (SWy-2-Mg) was characterized by a main structure composed by $21 \%$ of $1 \mathrm{~W}$ layer types with major contribution of the bihydrated ones (79\%). By reaching $80 \% \mathrm{RH}$, a different configuration composed by $7 \%, 65 \%$, and $28 \%$ attributed, respectively, to $1 \mathrm{~W}, 2 \mathrm{~W}$, and $3 \mathrm{~W}$ hydration states is manifested (Figure 4). On the contrary, along the dehydration process, the decrease of the $\mathrm{RH}$ values from $80 \%$ to $30 \%$ leads to a gradual emptying of the microscopic porosity corresponding to the reduction of the interlamellar water molecule abundances. Indeed, successive $3 \mathrm{~W} \rightarrow 2 \mathrm{~W}$ and $2 \mathrm{~W} \rightarrow 1 \mathrm{~W}$ transitions are observed over this $\mathrm{RH}$ range, where the structure is composed at $30 \%$ RH by $19 \%, 75 \%$, and $6 \%$, respectively, for $1 \mathrm{~W}, 2 \mathrm{~W}$, and $3 \mathrm{~W}$ layer types. An obvious transformation on the structural composition and a notable change on the hydration behavior were distinguished towards the lowest $\mathrm{RH}$ domain starting from $20 \% \mathrm{RH}$ (rehydration process) to the end of the cycle at $40 \% \mathrm{RH}$ (rehydration process). In fact, fast emptying of the interlamellar spaces from water planes was noted by decreasing the \% $\mathrm{RH}$ rates during the dehydration procedure where the $2 \mathrm{~W}$ layer-type contribution decreases rapidly with a complete disappearance of the $3 \mathrm{~W}$ layer from the structure (Figure 4). Over this $\mathrm{RH}$ range, fast increasing of the $1 \mathrm{~W}$ layer-type contribution was noted, which dominates the structure until the end of the cycle (Figure 4 ).

\subsection{Quantifying Interlamellar Space Content during the Second Cycle}

3.2.1. Qualitative XRD Investigation. Experimental XRD patterns obtained under controlled $\mathrm{RH}$ condition along the second cycle are represented with the respective contributions of the various MLSs used to calculate profiles in Figure 5.

The correlation between FWHM and the $\xi$ parameter (Table 3) proposes that over a large $\mathrm{RH}$ range extending between $30 \%$ (dehydration process) $\leq \mathrm{RH} \leq 70 \% \mathrm{RH}$ (hydration procedure), the structure is characterized by an interstratified hydration character. However, the study suggests homogenous hydration behaviors with decreasing the $\mathrm{RH}$ values from $80 \%$ to $40 \%$ over the second dehydration procedure (Table 3 ).

Evolution of the layer thickness $\left(d_{001}\right)$ as function of the $\mathrm{RH} \%$, along the second cycle, was characterized by the appearance of a clear hysteresis at the $\mathrm{RH}$ range extending between $40 \%$ and $10 \%$ (Figure 3 ). Indeed, a fast shift of the $d_{001}$ spacing values from $15.39 \AA$ at $40 \% \mathrm{RH}$ to $12.90 \AA$ at $10 \%$ $\mathrm{RH}$ was observed. However, a slow $d_{001}$ value progress is noted by inversing the $\mathrm{RH} \%$ orientation. Over these $\mathrm{RH}$ domains, the $d_{001}$ is attributed to an interstratified $2 \mathrm{~W}-1 \mathrm{~W}$ hydration state.

3.2.2. Theoretical Models and the Hydration Properties. Optimum structural parameters used to fit experimental XRD patterns in the case of the second cycle are summarized in Table 4. The quantitative XRD investigation demonstrates that all calculated theoretical models which allow reproducing the 001 reflections are characterized by heterogeneous hydration states composed of two different MLSs with diverse relative proportions of layer types (Figures 5(a) and 5(b)).

Evolution of different layer type contributions as a function of $\mathrm{RH}$ is detailed in Figure 6. With decreasing the $\mathrm{RH} \%$ during the first dehydration procedure, a slow transition from the $2 \mathrm{~W}$ to $1 \mathrm{~W}$ state was observed between $40 \%$ $\mathrm{RH}$ and $20 \% \mathrm{RH}$ where the smectite crystallite presents major contributions of the $2 \mathrm{~W}$ layer types.

A notable increase of the $1 \mathrm{~W}$ layer proportion, towards the lowest RH condition (i.e., $10 \% \mathrm{RH}$ ), is detected. At this $\mathrm{RH}$ rate, the structure is reproduced by $70 \%$ of the monohydrated states (1W) and $30 \%$ of the bihydrated ones (Figure 6). 

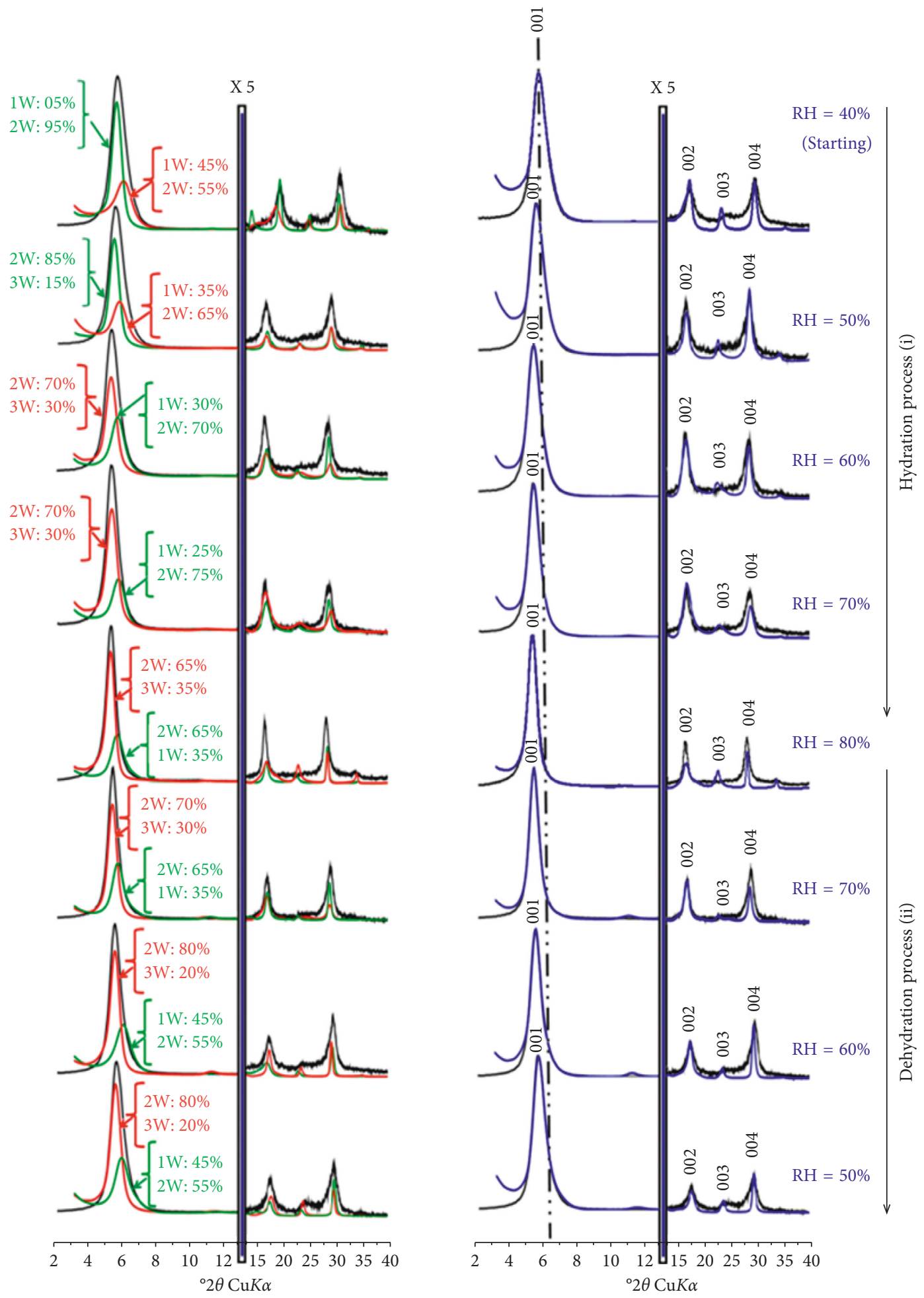

(a)

FIgUre 2: Continued. 

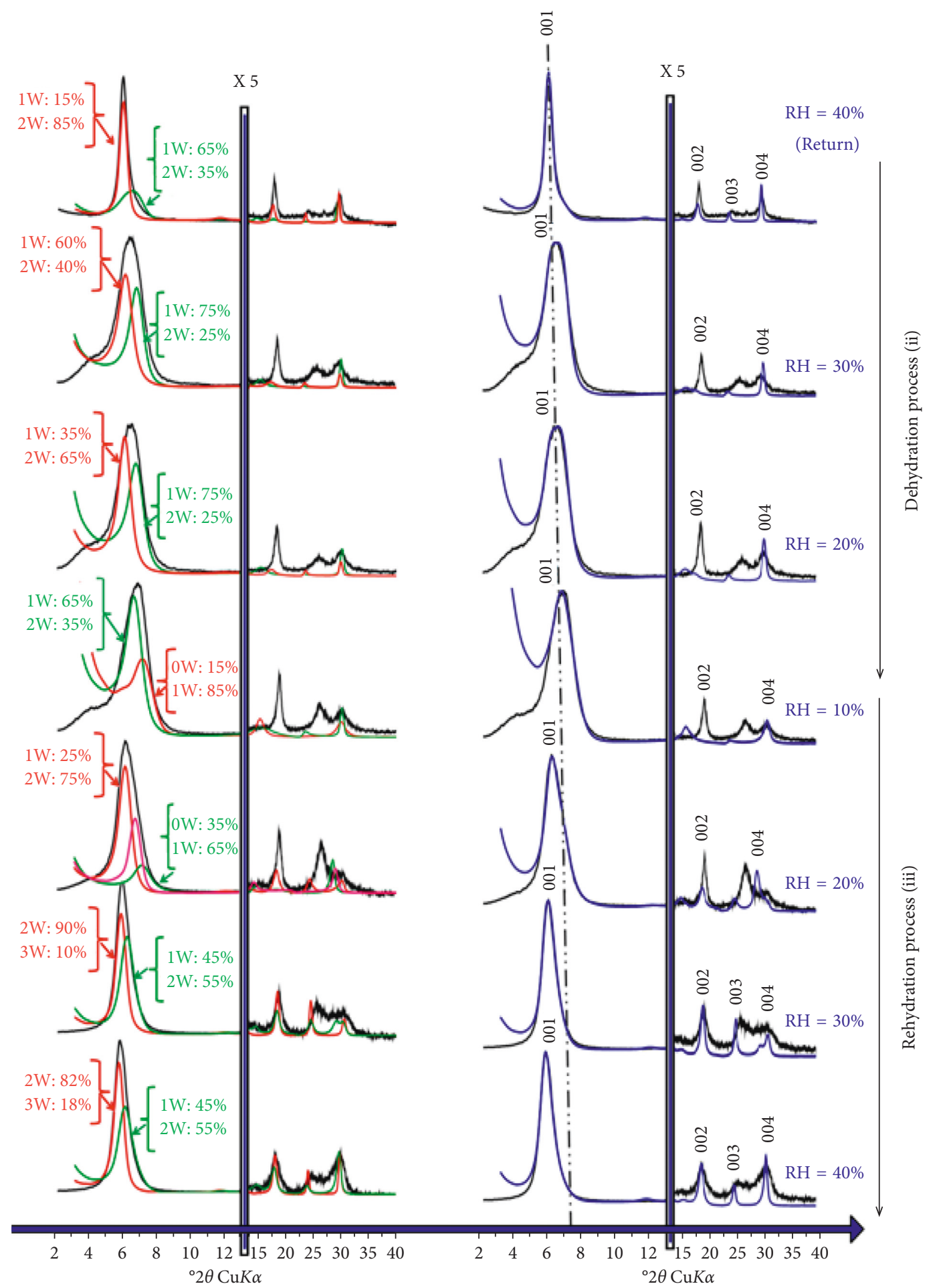
TABLE 1: Qualitative XRD investigation versus $\% \mathrm{RH}$ in the case of the first hydration-dehydration cycle.

\begin{tabular}{|c|c|c|c|c|c|}
\hline & $\% \mathrm{RH}$ & $d_{001}$ & FWHM & $\xi$ & Character \\
\hline \multirow{5}{*}{ Hydration process } & 40 & 15.52 & 1.03 & 0.77 & I \\
\hline & 50 & 15.96 & 1.09 & 0.67 & I \\
\hline & 60 & 16.46 & 0.94 & 0.47 & $\mathrm{I}$ \\
\hline & 70 & 16.60 & 0.82 & 0.34 & $\mathrm{H}$ \\
\hline & 80 & 16.74 & 0.68 & 0.21 & $\mathrm{H}$ \\
\hline \multirow{7}{*}{ Dehydration process } & 70 & 16.40 & 0.70 & 0.13 & $\mathrm{H}$ \\
\hline & 60 & 16.07 & 0.78 & 0.18 & $\mathrm{H}$ \\
\hline & 50 & 15.70 & 0.89 & 0.15 & $\mathrm{H}$ \\
\hline & 40 & 15.32 & 0.91 & 0.26 & $\mathrm{H}$ \\
\hline & 30 & 14.98 & 0.95 & 0.41 & $\mathrm{I}$ \\
\hline & 20 & 14.42 & 1.34 & 0.48 & I \\
\hline & 10 & 12.90 & 1.50 & 0.72 & I \\
\hline \multirow{3}{*}{ Rehydration process } & 20 & 13.55 & 1.54 & 0.53 & I \\
\hline & 30 & 13.80 & 1.50 & 0.83 & I \\
\hline & 40 & 15.20 & 1.48 & 0.20 & I \\
\hline
\end{tabular}

Note: position $d_{001}$ and FWHM of the 001 reflection are given in angstroms and in ${ }^{\circ} 2 \theta \mathrm{CuK \alpha}$, respectively. The $\xi$ parameter which accounts for the departure from rationality of the 001 reflection series is calculated as the standard deviation of the $l \times d_{001}$ values calculated for the $\mathrm{Xi}$ measurable reflections $(\mathrm{Xi}=3$ in this case) over the $2-40^{\circ} 2 \theta \mathrm{CuK \alpha}$ angular range. (I) and (H) indicate Interstratified hydration character and Homogeneous hydration character.

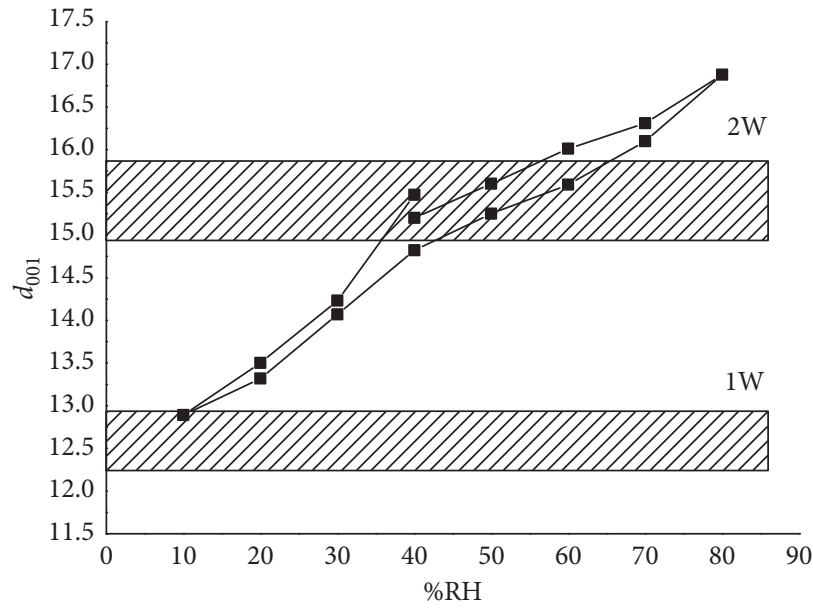

(a)

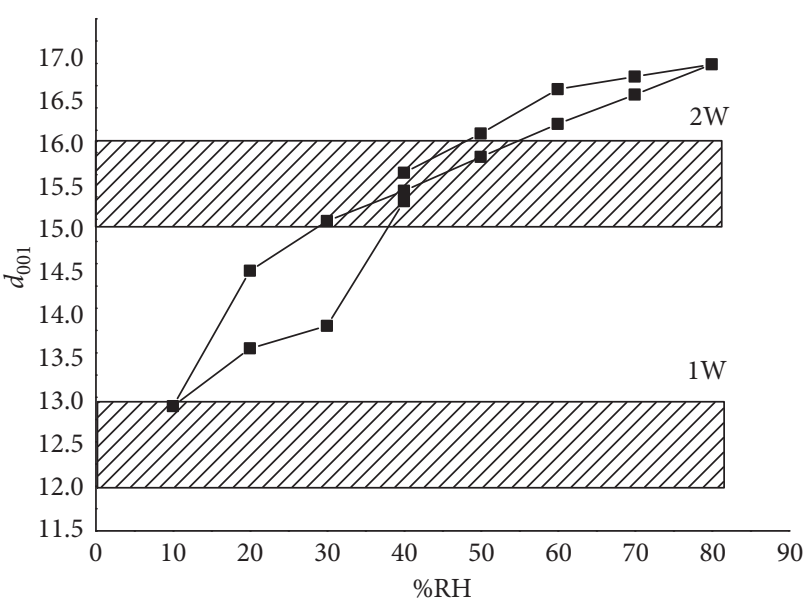

(b)

FIGURE 3: Evolution of the given $d_{001}$ spacing values according to $\% \mathrm{RH}$ values during the first and the second cycle.

three layer types including $1 \mathrm{~W}, 2 \mathrm{~W}$, and $3 \mathrm{~W}$ with a clear dominance of the bihydrated phases (2W). During the second dehydration procedure performed by decreasing the $\mathrm{RH} \%$ from the highest $\mathrm{RH}$ value (i.e., $80 \% \mathrm{RH}$ ) to the starting point (i.e., $40 \% \mathrm{RH}$ ), a gradual emptying of the interlamellar spaces from water is noted. Theoretical models propose structures characterized by the major proportion of the $2 \mathrm{~W}$ layer types which kept the highest proportion until the end of the cycle (Figure 6).

\section{Discussion}

4.1. RH, Interlamellar Water Amounts, and Ionic Radius. The continuous variation of the $\mathrm{RH}$ values along both cycles automatically brings a sequential transition between different hydration states in the interlayer spaces of SWy-2Mg complex, which logically leads to a continuous change on the interlayer water amount and distribution.

Figure 7 represents a comparison between the interlamellar water molecule content evolution along the first and the second cycle, which establishes the dependence of the hydration behavior progression on the sequence variation and orientation of the $\mathrm{RH}$ values clearly. In fact, a dissimilar progression of the water amount was perceived in three principal RH fields: Over the first $\mathrm{RH}$ section spreading between $50 \% \mathrm{RH}$ and $80 \% \mathrm{RH}$, labeled (I), the interlayer water amounts retained in the structure were more important in the case of first hydration-dehydration cycle than in the second one. An analogous hydration behavior of the studied complex is observed in the short $\mathrm{RH}$ domain over the second domain 
TABLE 2: Structural parameters used to reproduce experimental patterns of SWy-2-Mg complex as a function of RH along the first hydration-dehydration cycle.

\begin{tabular}{|c|c|c|c|c|c|c|c|c|}
\hline & $\% \mathrm{RH}$ & $\%$ of MLS & $\%$ of $0 \mathrm{~W} / 1 \mathrm{~W} / 2 \mathrm{~W} / 3 \mathrm{~W}-\mathrm{R}^{*}$ & $\begin{array}{c}\text { L.Th } \\
0 \mathrm{~W} \\
1 \mathrm{~W} \\
2 \mathrm{~W} \\
3 \mathrm{~W}\end{array}$ & $\begin{array}{c}n \mathrm{H}_{2} \mathrm{O} \\
0 \mathrm{~W} \\
1 \mathrm{~W} \\
2 \mathrm{~W} \\
3 \mathrm{~W}\end{array}$ & $\begin{array}{c}\mathrm{ZH}_{2} \mathrm{O} \\
0 \mathrm{~W} \\
1 \mathrm{~W} \\
2 \mathrm{~W} \\
3 \mathrm{~W}\end{array}$ & $\begin{array}{l}\mathrm{Z}_{\mathrm{Mg}} \\
0 \mathrm{~W} \\
1 \mathrm{~W} \\
2 \mathrm{~W} \\
3 \mathrm{~W}\end{array}$ & M \\
\hline \multirow{19}{*}{ Hydration } & \multirow{3}{*}{40 (start) } & 65 & 0/45/55/0-R0 & - & - & - & - & \\
\hline & & 35 & 0/05/95/0-R0 & 12.30 & $\begin{array}{l}2 \\
4\end{array}$ & $\begin{array}{c}09.60 \\
1000 / 1450\end{array}$ & $\begin{array}{l}09.60 \\
1240\end{array}$ & 8 \\
\hline & & & & $\begin{array}{c}15.00 \\
-\end{array}$ & - & $\begin{array}{c}10.00 / 14.50 \\
-\end{array}$ & $\begin{array}{c}12.40 \\
-\end{array}$ & \\
\hline & \multirow{4}{*}{50} & 70 & 0/35/65/0-R1 & - & - & - & - & \\
\hline & & 30 & 0/0/85/15-R0 & 12.30 & 2 & 09.70 & 09.70 & 8 \\
\hline & & & & 15.75 & 4 & $10.00 / 14.50$ & 12.40 & \\
\hline & & & & 18.00 & 6 & $10.60 / 14.80 / 16.20$ & 14.80 & \\
\hline & \multirow{4}{*}{60} & 60 & 0/0/70/30-R0 & - & - & - & - & \\
\hline & & 40 & 0/30/70/0-R1 & 12.40 & 2.5 & 09.80 & 09.80 & \\
\hline & & & & 15.75 & 5 & $10.00 / 14.70$ & 12.40 & 7 \\
\hline & & & & 18.00 & 6 & $10.60 / 14.80 / 16.20$ & 14.80 & \\
\hline & \multirow{4}{*}{70} & 80 & 0/0/70/30-R0 & - & - & - & - & \\
\hline & & 20 & 0/25/5/0-R1 & 12.65 & 2.5 & 09.80 & 09.80 & 8 \\
\hline & & & & 15.80 & 5.6 & $10.00 / 14.85$ & 12.60 & \\
\hline & & & & 18.00 & 6 & $10.60 / 14.70 / 16.40$ & 14.70 & \\
\hline & \multirow{4}{*}{80} & 80 & 0/0/65/35-R1 & - & - & - & - & 11 \\
\hline & & 20 & 0/65/35/0-R1 & 12.65 & 3 & 10.40 & 09.60 & \\
\hline & & & & 15.80 & 6 & $10.00 / 14.50$ & 12.70 & \\
\hline & & & & 18.40 & 6 & $10.60 / 14.50 / 16.80$ & 16.80 & \\
\hline \multirow{28}{*}{ Dehydration } & \multirow{4}{*}{70} & 70 & 0/0/70/30-R0 & - & - & - & - & \\
\hline & & 30 & 0/35/65/0-R0 & 12.40 & 2.5 & 10.20 & 09.20 & 10 \\
\hline & & & & 15.75 & 6 & $10.00 / 14.90$ & 12.60 & \\
\hline & & & & 18.40 & 6 & $10.40 / 14.90 / 16.70$ & 14.70 & \\
\hline & \multirow{4}{*}{60} & 60 & 0/0/80/20-R1 & - & - & - & - & \\
\hline & & 35 & 0/45/55/0-R1 & 12.15 & 2.5 & 10.30 & 10.30 & 10 \\
\hline & & & & 15.50 & 5 & $09.50 / 14.70$ & 12.50 & \\
\hline & & & & 18.30 & 6 & $10.70 / 14.70 / 16.70$ & 14.70 & \\
\hline & \multirow{4}{*}{50} & 50 & 0/0/80/20-R0 & - & - & - & - & - \\
\hline & & 50 & 0/45/55/0-R1 & 12.00 & 2.5 & 10.30 & 10.30 & 10 \\
\hline & & & & 15.20 & 4 & 09.60/14.50 & 12.40 & \\
\hline & & & & 18.30 & 6 & $10.60 / 14.50 / 16.70$ & 14.50 & \\
\hline & \multirow{4}{*}{40} & 58 & 0/0/82/18-R1 & - & - & - & - & \\
\hline & & 42 & 0/45/55/0-R1 & 12.30 & 2.5 & 10.00 & 10.00 & 10 \\
\hline & & & & 14.95 & 4 & $09.70 / 14.90$ & 12.60 & \\
\hline & & & & 18.30 & 6 & $10.20 / 14.70 / 16.90$ & 14.70 & \\
\hline & \multirow{4}{*}{30} & 58 & 0/0/90/10-R0 & - & - & - & - & \\
\hline & & 42 & 0/45/55/0-R1 & 12.50 & 2 & 10.00 & 10.00 & 10 \\
\hline & & & & 14.95 & 3.2 & $10.30 / 14.50$ & 12.60 & \\
\hline & & & & 18.20 & 6 & $10.00 / 14.70 / 16.90$ & 14.70 & \\
\hline & \multirow{4}{*}{20} & 40 & $35 / 65 / 0 / 0-\mathrm{R} 1$ & 10.70 & - & - & 9.00 & 9 \\
\hline & & 37.80 & 0/25/75/0-R1 & 12.50 & 2 & 09.70 & 09.70 & \\
\hline & & 22.20 & 0/80/20/0-R0 & 14.75 & 3.6 & $10.30 / 14.50$ & 12.40 & \\
\hline & & & & - & - & - & - & \\
\hline & \multirow{4}{*}{10} & 60 & 15/85/0/0-R0 & 10.20 & - & 09.00 & 9.00 & \\
\hline & & 40 & 0/65/35/0-R0 & 12.00 & 1.5 & 09.70 & 09.70 & 7 \\
\hline & & & & 14.75 & 3.6 & $10.30 / 14.00$ & 12.40 & \\
\hline & & & & - & - & - & - & \\
\hline
\end{tabular}


TABLE 2: Continued.

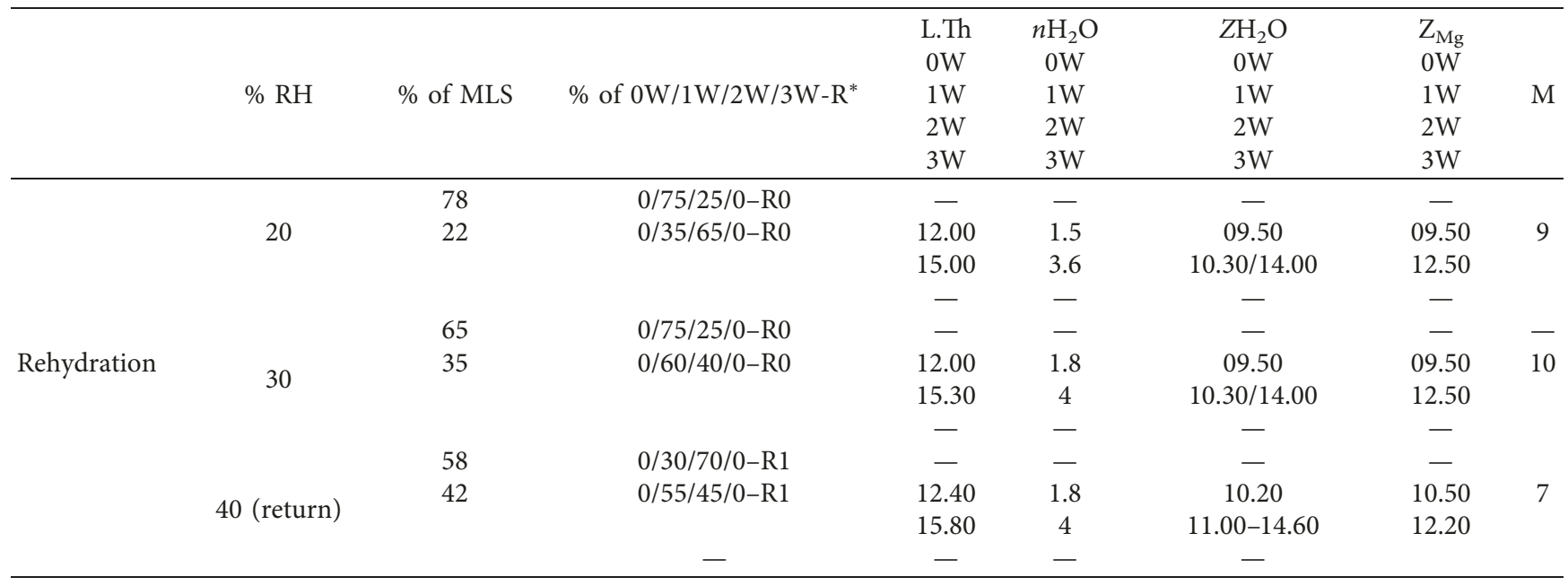

Note: $3 \mathrm{~W}, 2 \mathrm{~W}, 1 \mathrm{~W}$, and $0 \mathrm{~W}$ are attributed to the layer hydration state. $\mathrm{R} *$ : Reichweit $(\mathrm{R})$ "f factor. R0 and R1 describe the MLS with random interstratifications or with partial segregation, respectively. L.Th: layer thickness in $\AA$. $n \mathrm{H}_{2} \mathrm{O}$ : number of $\mathrm{H}_{2} \mathrm{O}$ molecule per half unit cell. $\mathrm{Z}_{\mathrm{H} 2 \mathrm{O}}$ : position along c* axis of $\mathrm{H}_{2} \mathrm{O}$ molecule. $\mathrm{Z}_{\mathrm{Mg}}$ : position of exchangeable cations per half unit cell calculated along $\mathrm{c}^{*}$ axis. M: average layer number per stacking. $\mathrm{n}_{\mathrm{Mg}}$ : number of $\mathrm{H}_{2} \mathrm{O}$ molecule per half unit cell fixed to 0.15 , indicating full saturation of the cationic exchange capacity CEC of the minerals.

(1)

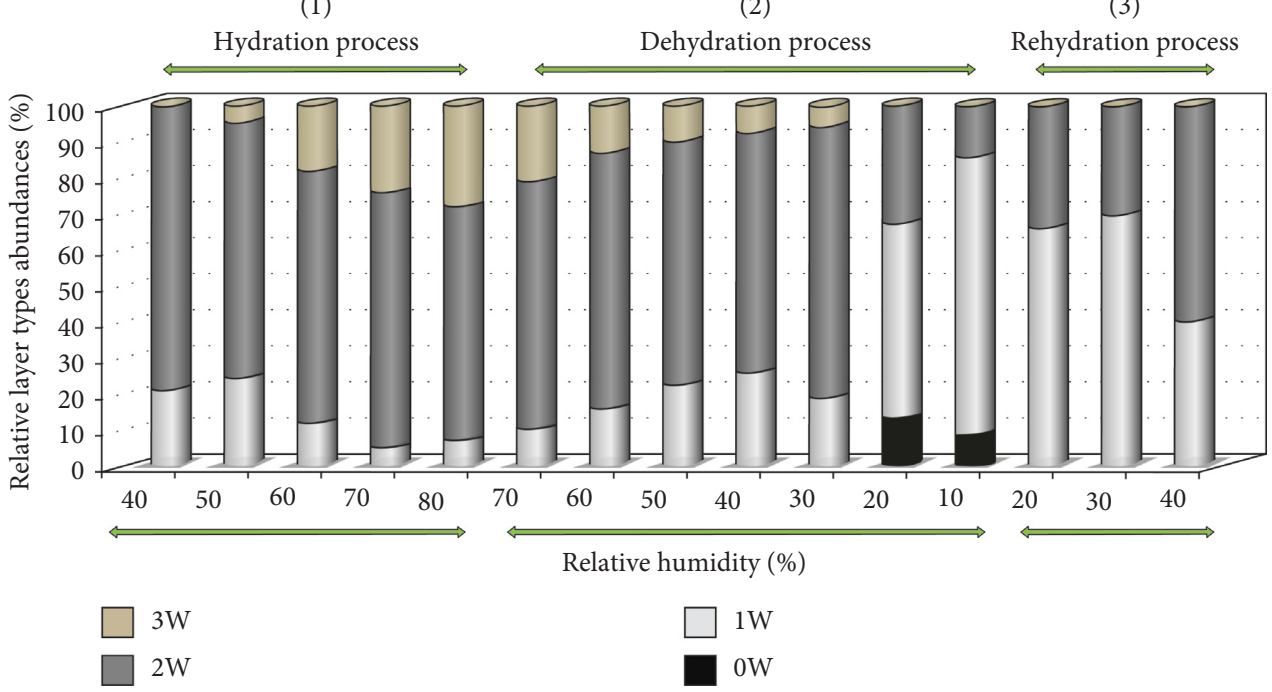

FIGURE 4: Relative contribution progress of the different layer types (summing up all mixed-layer structures) as function of the RH \% along the first cycle.

(II) between 50 and $40 \% \mathrm{RH}$ of both cycles. However, at the lower RH fields (III), quantitative results prove that the calculated interlamellar water amounts were more important in the case of the second cycle than the first one.

Such obtained result is in concordance with the previous work [52-54] where the same studied montmoriollonite was saturated with other bivalent cations characterized by different ionic radius $\left(\mathrm{Ni}^{2+}, \mathrm{Hg}^{2+}\right.$, and $\mathrm{Ba}^{2+}$ ) and have undergone the same "in situ" adsorption/desorption sequences. Results derived from modeling of X-ray diffraction (XRD) patterns related to the cited study have proven that the hydration mechanism at crystal scale of diverse samples was found to evolve gradually in different ways as a function of the applied cycles, thus proving the dependence of the progress of the swelling property of the montmorillonite on the sequence orientation, which means problem related to how the $\mathrm{RH}$ rates varied over the cycle.

On the contrary, the comparison between the development of the interlayer $\mathrm{H}_{2} \mathrm{O}$ molecule retained in the interlamellar spaces for the montmorillonite saturated by diverse bivalent cations $\left(\mathrm{Ba}^{2+}, \mathrm{Ni}^{2+}, \mathrm{Hg}^{2+}\right.$, and $\mathrm{Mg}^{2+}$ ) upon the first cycle and the second one (Figure 8 ) shows an analogous hydration performance between the SWy-2- 

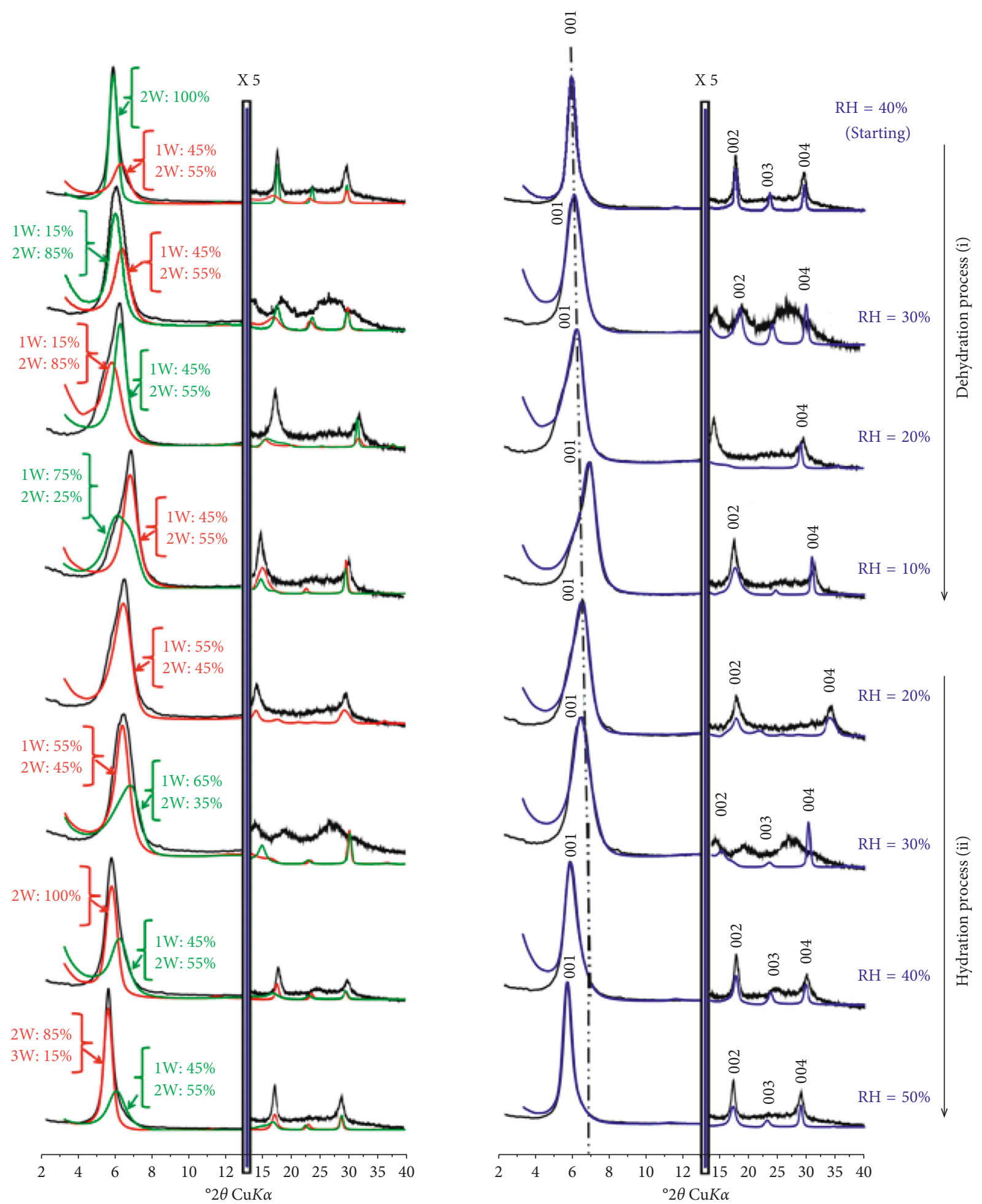

(a)

Figure 5: Continued. 


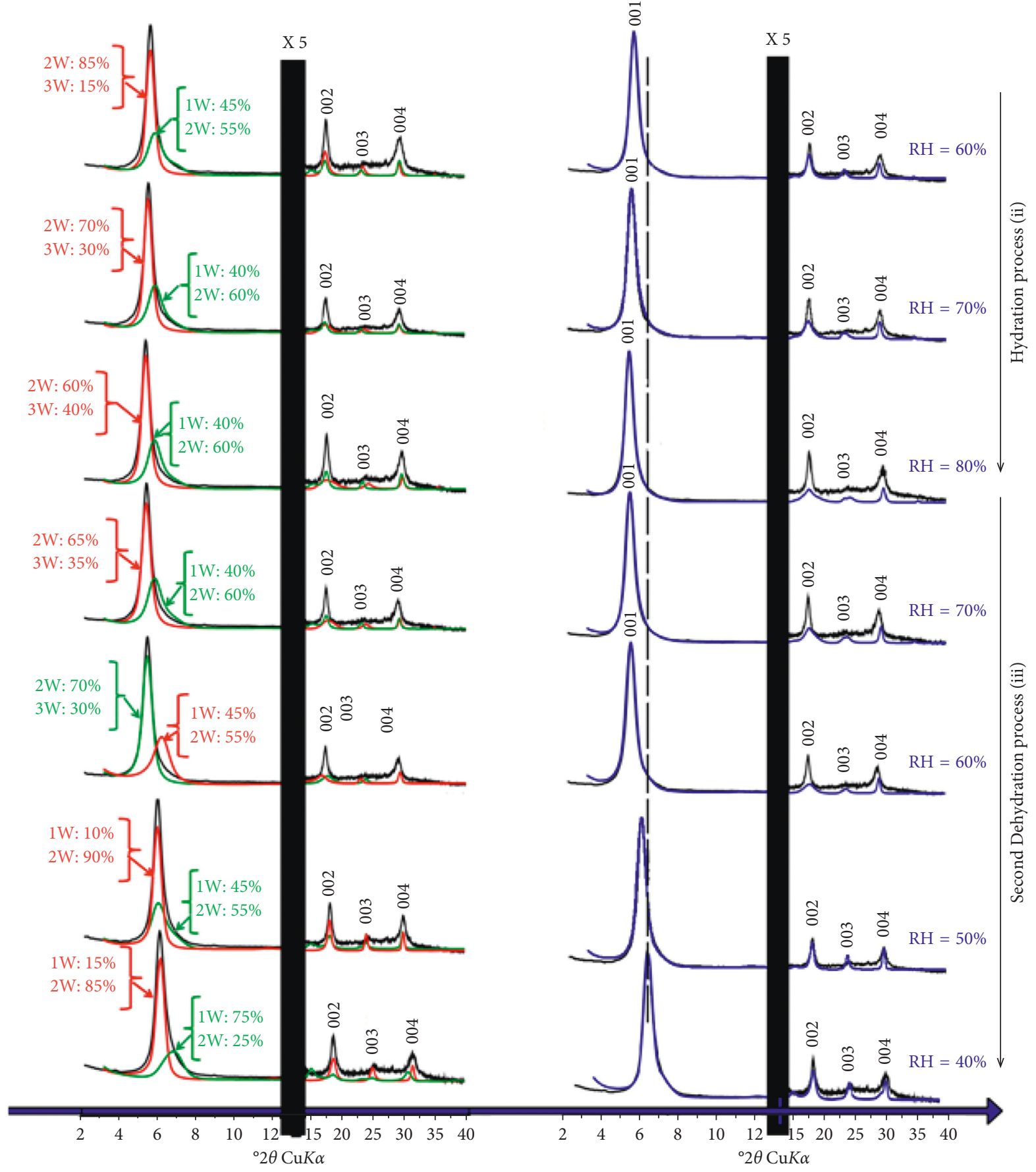

(b)

FIGURE 5: Best agreement between experimental (black line) and calculated (blue line) XRD patterns obtained using the respective contributions of the various MLSs (red and green line) in the case of the second cycle.

$\mathrm{Ni}$ and SWy-2-Mg. In fact, a clear hysteresis is observed in both cases indicating irreversible interlayer water progress during the hydration-dehydration cycles. However, location of $\mathrm{Ba}^{2+}$ and $\mathrm{Hg}^{2+}$ in exchangeable sites of the same matrix leads to more stability in interlamellar spaces of both structures; thus, the evolution of the interlayer water contents was more respected during the applied cycles. The assessment of these results revealed that the environmental solicitation performed by the continuous change of the $\mathrm{RH} \%$ affects deeply the hydration performance of the host materials (SWy-2) especially in presence of bivalent cations with the lowest ionic radius in their exchangeable sites. In fact, unlike the cations with little size $\left(\mathrm{Mg}^{2+}\right.$ and $\left.\mathrm{Ni}^{2+}\right)$, the huge size of $\mathrm{Ba}^{2+}$ and $\mathrm{Hg}^{2+}$ favors 
TABLE 3: Qualitative XRD investigation versus RH\% in the case of the second hydration-dehydration cycle.

\begin{tabular}{|c|c|c|c|c|c|}
\hline & $\% \mathrm{RH}$ & $d_{001}\left(\mathrm{~A}^{\circ}\right)$ & FWHM $\left({ }^{\circ} 2 \theta\right)$ & $\xi$ & Character \\
\hline \multirow{4}{*}{ Dehydration process } & 40 (start) & 15.47 & 1.40 & & I \\
\hline & 30 & 14.23 & 1.44 & 0.16 & I \\
\hline & 20 & 13.50 & 1.55 & 0.18 & I \\
\hline & 10 & 12.89 & 1.76 & 0.10 & $\mathrm{I}$ \\
\hline \multirow{7}{*}{ Hydration process } & 20 & 13.32 & 1.69 & 0.53 & $\mathrm{I}$ \\
\hline & 30 & 14.07 & 1.67 & 0.51 & I \\
\hline & 40 & 14.82 & 1.72 & 0.80 & I \\
\hline & 50 & 15.25 & 1.63 & 0.36 & I \\
\hline & 60 & 15.59 & 1.60 & 0.15 & I \\
\hline & 70 & 16.10 & 1.04 & 0.20 & I \\
\hline & 80 & 16.88 & 1.00 & 0.49 & $\mathrm{I}$ \\
\hline \multirow{4}{*}{ Second dehydration process } & 70 & 16.31 & 0.95 & 0.20 & $\mathrm{H}$ \\
\hline & 60 & 16.01 & 1.19 & 0.18 & I \\
\hline & 50 & 15.60 & 1.46 & 0.15 & I \\
\hline & 40 (return) & 15.20 & 1.60 & 0.10 & $\mathrm{I}$ \\
\hline
\end{tabular}

a decrease of the hydration heterogeneities degree and thus establish more stability of the crystal structure. Thus, the ionic radius of the bivalent compensator ions represents an intrinsic parameter which has important impact on the evolution of the hydration behaviors of the studied smectite.

The hydrous disruption that appears on the interlamellar spaces can be interpreted by the appearance of structural perturbation and new organization at the crystal scale versus the applied hydrous strain. Indeed, the hydration heterogeneity was explained in many studies by the disorder distribution of the surface charge sites which leads to heterogeneous structural composition responsible for such behaviors $[55,56]$.

Such structural perturbation is justified in the present work through quantitative XRD investigation. Indeed, all theoretical structural models suggest the coexistence of more than one mixed-layer structure (MLS) and propose continuous variations of the interlamellar spaces configurations whatever the interlayer bivalent cations nature (i.e., $\mathrm{Mg}^{2+}, \mathrm{Hg}^{2+}, \mathrm{Ba}^{2+}$, and $\mathrm{Ni}^{2+}$ ) and whatever the relative humidity rates that varied upon the applied cycles [52-54].

However, the unsteadiness of the material behavior face to the environmental surroundings changes represent inconvenience when using such mineral as natural barriers in industrial wastes and radioactive treatment specially in long-live storage application.

Indeed, [45] demonstrates that the cation-exchange process of Na-rich montmorillonite in contact with solution containing bivalent cations $\left(\mathrm{Cu}^{2+}\right.$ and $\left.\mathrm{Co}^{2+}\right)$ was affected when applied 15 hydration-dehydration cycles, created by continuous variation of $\mathrm{RH} \%$ rates. In this case, results derivatived from quantitative XRD analysis prove that the hydrous strain was accompanied by an obvious structural change characterized by a decrease in the amount of exchangeable sites which affect the selective exchange process.

In this regard, taking into account the change of surrounding environmental condition is crucial to avoid its consequence on the microstructure stability of the geotechnical barrier especially in long term.

4.2. Hydration Hysteresis. The comparison between the average hydration hysteresis and the evolution of the calculated standard deviation (SD) for all specimens along both cases of cycles were reported in Figure 9. The SD is generally used to quantify the amount of variation or dispersion of a set of data values. The comparison shows that every sample was characterized by different average hydration hysteresis as well as their associated SD as function of the applied cycle. This result confirms the impact of the RH sequence orientation on the hydration behavior of the studied montmorillonite whatever the nature of the bivalent cation present in their exchangeable sites.

Moreover, the evolution of the SD parameter versus RH\% over both cycles (Figure 10) indicate that for all studied complexes, the calculated SD values were more important for the major parts of the RH field in the case of the second cycle than in the first one. The high SD values can be interpreted by the appearance of important structural fluctuations and perturbation on the hydration properties over the second cycle comparing with the first one. However, when focusing the progress of the SD values' evolution during the first cycle, the obtained results show that the calculated SD decreases gradually for different samples when increasing RH values, which indicates more structural stability trends for all studied complexes at the highest $\mathrm{RH}$ fields.

On the contrary, according to the literature [20, 28, 33], the classification of the divalent cations used in this work (based on their ionic potential) should respect the following order: $\mathrm{Mg}^{2+}>\mathrm{Ni}^{2+}>\mathrm{Hg}^{2+}>\mathrm{Ba}^{2+}$. However, the exploitation of Figure 9, by following the evolution of different average hydration hysteresis as function of the $\%$ $\mathrm{RH}$, indicates that this classification was low respected in major parts of the explored RH fields and in both cycle types. Indeed, at the exception of narrow $\mathrm{RH}$ fields 
TABLE 4: Structural parameters used to fit experimental patterns of SWy-2-Mg complex as a function of $\mathrm{RH}$ along the second hydrationdehydration cycle.

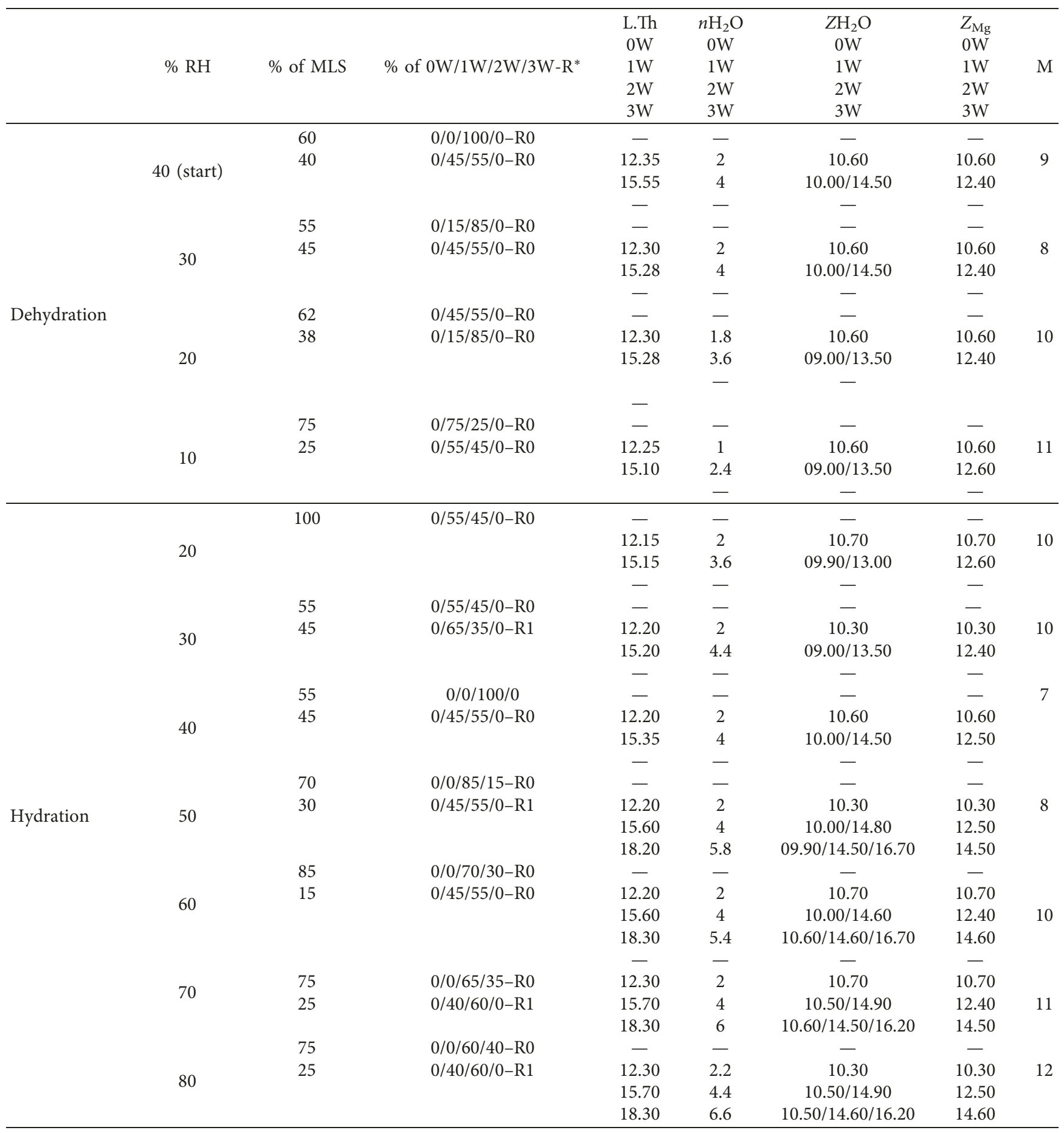


TABle 4: Continued.

\begin{tabular}{|c|c|c|c|c|c|c|c|c|}
\hline & & & & $\begin{array}{l}\text { L.Th } \\
\text { 0W }\end{array}$ & $\begin{array}{c}n \mathrm{H}_{2} \mathrm{O} \\
0 \mathrm{~W}\end{array}$ & $\begin{array}{c}\mathrm{ZH}_{2} \mathrm{O} \\
0 W\end{array}$ & $\begin{array}{l}Z_{\mathrm{Mg}} \\
0 \mathrm{~W}\end{array}$ & \\
\hline & $\% \mathrm{RH}$ & $\%$ of $\mathrm{MLS}$ & $\%$ of $0 \mathrm{~W} / 1 \mathrm{~W} / 2 \mathrm{~W} / 3 \mathrm{~W}-\mathrm{R}^{*}$ & $1 \mathrm{~W}$ & $1 \mathrm{~W}$ & $1 \mathrm{~W}$ & $1 \mathrm{~W}$ & M \\
\hline & & & & $2 \mathrm{~W}$ & $2 \mathrm{~W}$ & $2 \mathrm{~W}$ & $2 W$ & \\
\hline & & & & $3 \mathrm{~W}$ & $3 \mathrm{~W}$ & $3 \mathrm{~W}$ & $3 \mathrm{~W}$ & \\
\hline & & 65 & 0/0/70/30-R0 & - & - & - & - & \\
\hline & 70 & 35 & $0 / 60 / 40 / 0-\mathrm{R} 1$ & 12.20 & 2.2 & 10.30 & 10.30 & \\
\hline & 10 & & & 15.70 & 4.4 & $10.50 / 14.90$ & 12.50 & 12 \\
\hline & & & & 18.20 & 6.6 & $10.50 / 14.60 / 16.20$ & 14.60 & \\
\hline & & 65 & 0/0/85/15-R0 & - & - & - & - & \\
\hline & & 35 & 0/45/55/0-R1 & 12.30 & 2 & 10.20 & 10.20 & \\
\hline & 60 & & & 15.70 & 4 & $10.50 / 14.80$ & 12.50 & 11 \\
\hline Dehydration & & & & 18.20 & 6 & $10.50 / 14.60 / 16.20$ & 14.60 & \\
\hline Denyaration & & 55 & 0/10/90/0-R0 & - & - & - & - & \\
\hline & 50 & 45 & $0 / 45 / 55 / 0-\mathrm{R} 1$ & 12.20 & 2 & 10.20 & 10.20 & \\
\hline & 50 & & & 15.15 & 4 & $10.50 / 14.80$ & 12.50 & 11 \\
\hline & & & & - & - & - & - & \\
\hline & & 66 & 0/15/85/0-R0 & - & - & - & - & 12 \\
\hline & 40 (return) & 34 & 0/65/35/0-R1 & 12.00 & 2 & 09.70 & 09.70 & \\
\hline & 40 (return) & & & 15.15 & 4 & $10.00 / 14.50$ & 12.40 & \\
\hline & & & & - & - & - & - & \\
\hline
\end{tabular}

$n_{\mathrm{Mg}}$ : number of $\mathrm{H}_{2} \mathrm{O}$ molecule per half unit cell fixed to 0.15 , indicating full saturation of the cationic exchange capacity CEC of the minerals.

(1)

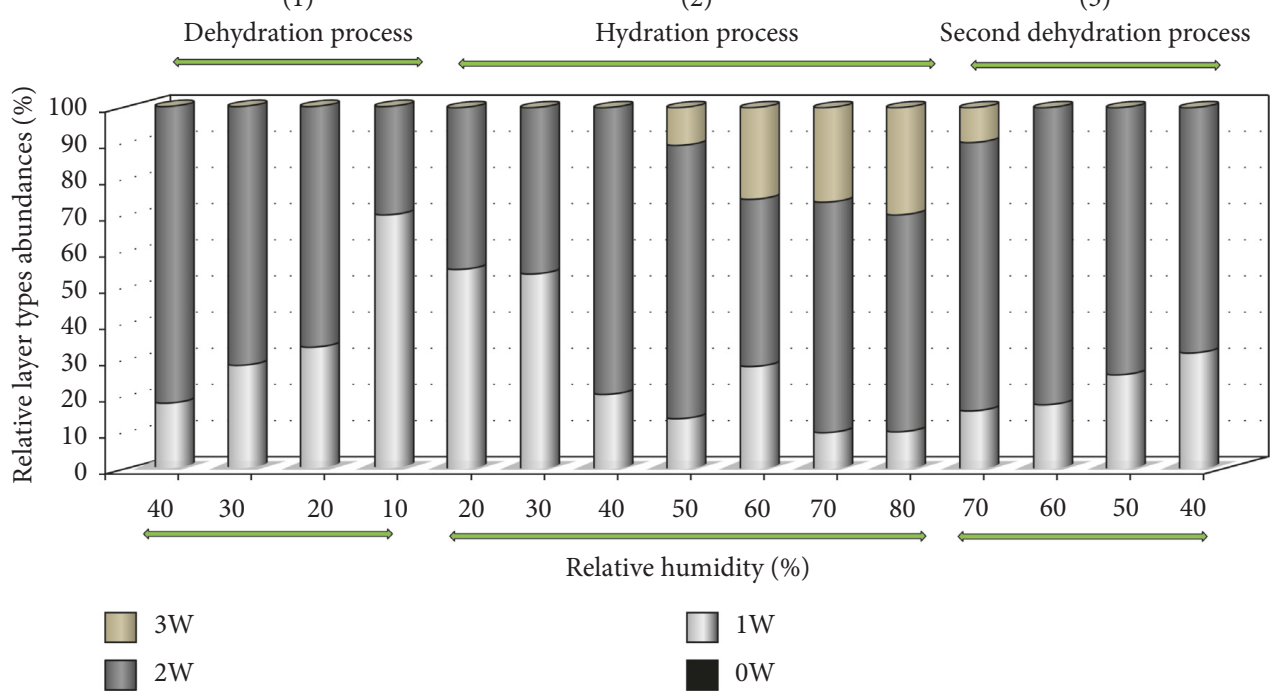

FiguRE 6: Evolution of the relative contribution of the different layer types (summing up all MLSs) as function of the RH\% in the case of the second cycle.

extending between $10 \%$ and $30 \%$ during the second cycle (Figure 9), the classification varied arbitrarily between different cations and changed randomly from an $\mathrm{RH}$ field to others ones.

As a consequence of this last result, the ionic potential cannot explain or justify the hydration behavior evolution of the montmorillonite saturated with bivalent cations when submitted to continuous changes of the $\mathrm{RH} \%$. In this regard, the water retention mechanism and the crystalline swelling of this smectite became more complex phenomenon under this type of environmental surrounding condition change. In fact, several factors contribute simultaneously to govern the interlamellar hydration processes, and their combined impacts complicate the well understanding of the interlayer swelling process.

\section{Conclusion}

This work focuses on the detailed hydration behavior response of an Mg-rich montmorillonite when it undergoes an environmental solicitation created by continuous variation of the $\mathrm{RH} \%$ along two different hydration-dehydration 


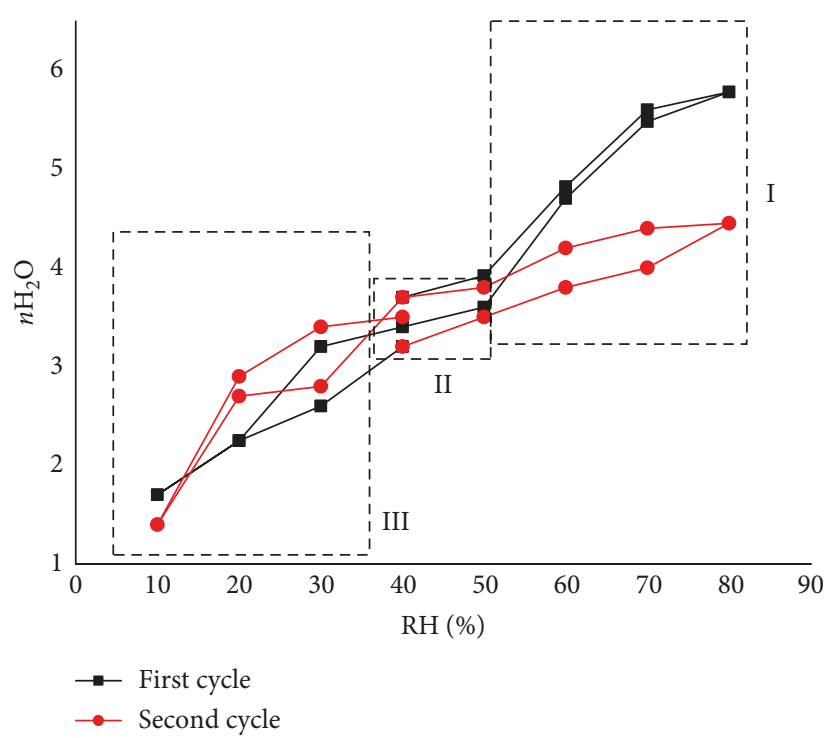

FIGURE 7: Development of the interlayer water contents as function of the $\mathrm{RH} \%$ along the first and the second cycles in the case of SWy-2-Mg complex.
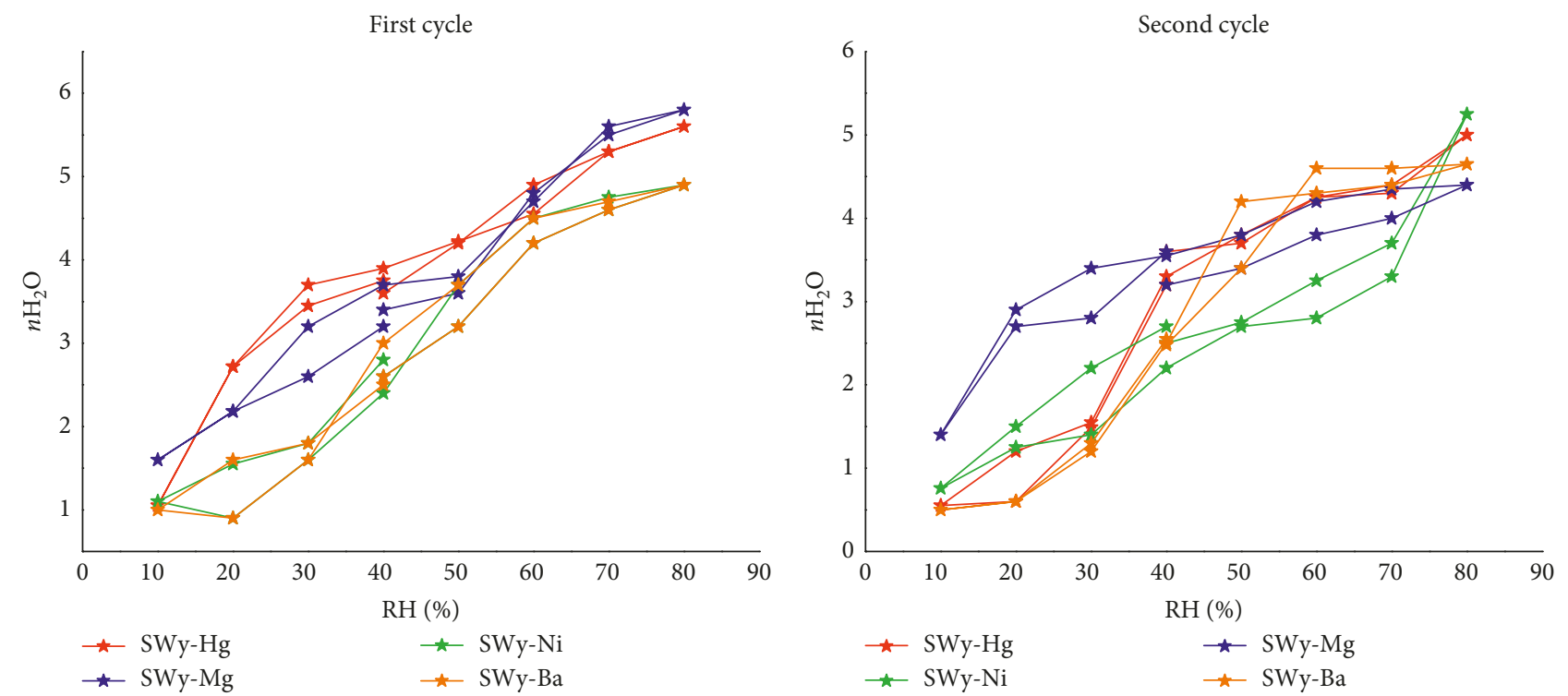

Figure 8: Comparison between the evolutions of the interlamellar water amount of the montmorillonite exchanged with different bivalent cations during the cycles.

cycles. Quantitative analysis is mainly based on XRDmodeling approach. The evolution of the hydration properties of the studied sample is quantified and followed every $10 \% \mathrm{RH}$ upon both cycles. The obtained results are compared with the hydration behaviors of $\mathrm{Hg}-$, Ba-, and Ni-rich montmorillonite studied in the same environmental condition changes.

The main results obtained through quantitative XRD investigation shows the following:

(i) The hydration behavior of the studied sample (i.e., SWy-2-Mg) strongly depended on the sequence orientation of the RH that varied over cycles. (ii) The proposed theoretical models describing the evolution of the structural properties suggests the coexistence of more than one MLS indicating the hydration heterogeneity character for the $\mathrm{SWy}-2-\mathrm{Mg}$ whatever the $\mathrm{RH} \%$ sequence orientation.

(iii) The montmorillonite's interlamellar water content growth was dependent on the nature of the bivalent exchangeable cations. In fact, the presence of $\mathrm{Mg}^{2+}$ as well as $\mathrm{Ni}^{2+}$ ions in the structure leads an irreversible interlayer water content process confirmed by the appearance of a hydration hysteresis. However, the location of cations with largest ionic radius like $\mathrm{Ba}^{2+}$ and $\mathrm{Hg}^{2+}$, in exchangeable sites, was 

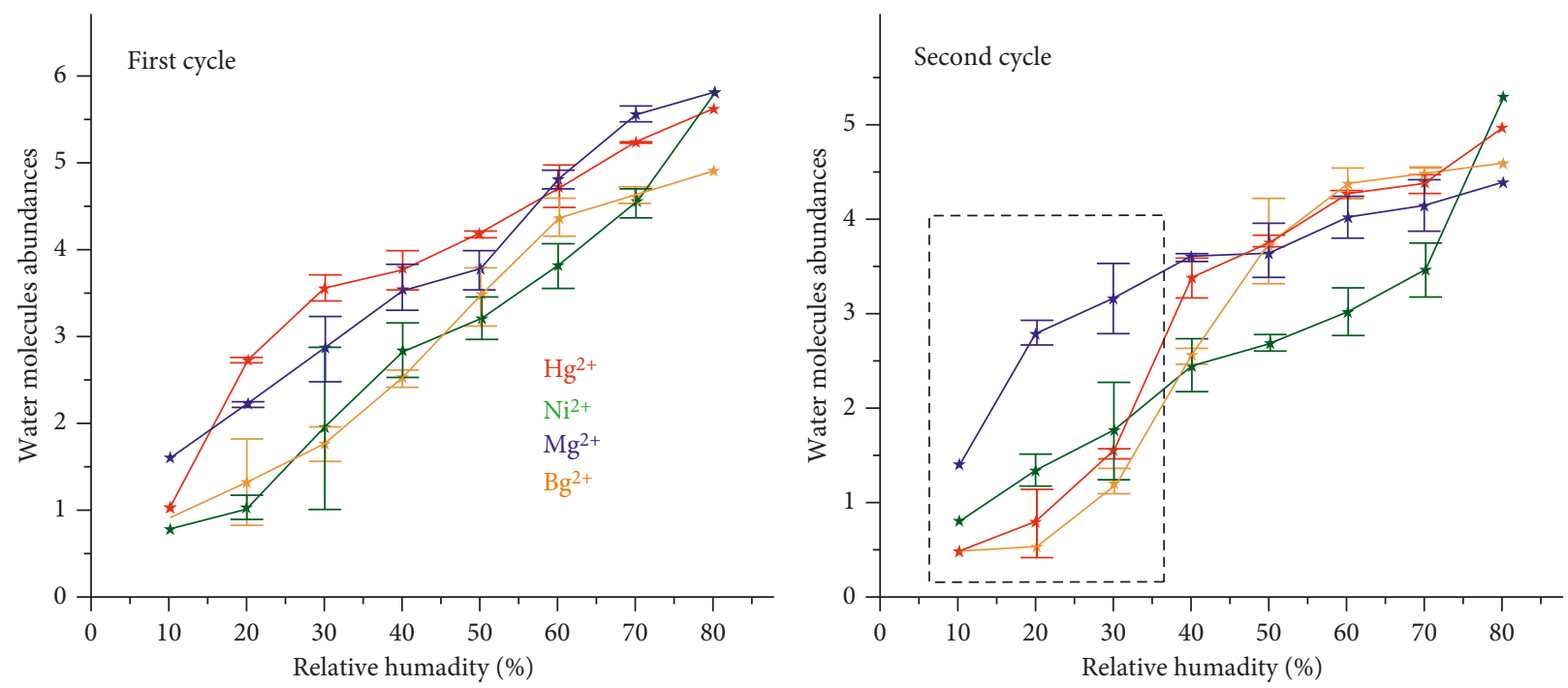

$$
\begin{aligned}
& \text { \# Average hydratuin hysteresis } \\
& \text { I Associated SD } \\
& \text { *- Average hydratuin hysteresis } \\
& \text { 工 Associated SD } \\
& \text { * Average hydratuin hysteresis } \\
& \text { I Associated SD } \\
& \text { *- Average hydratuin hysteresis } \\
& \text { I Associated SD }
\end{aligned}
$$

FIGURE 9: Average hydration hysteresis and the associated SD for the montmorillonite saturated with different bivalent cations in the cases of the first and the second cycles.
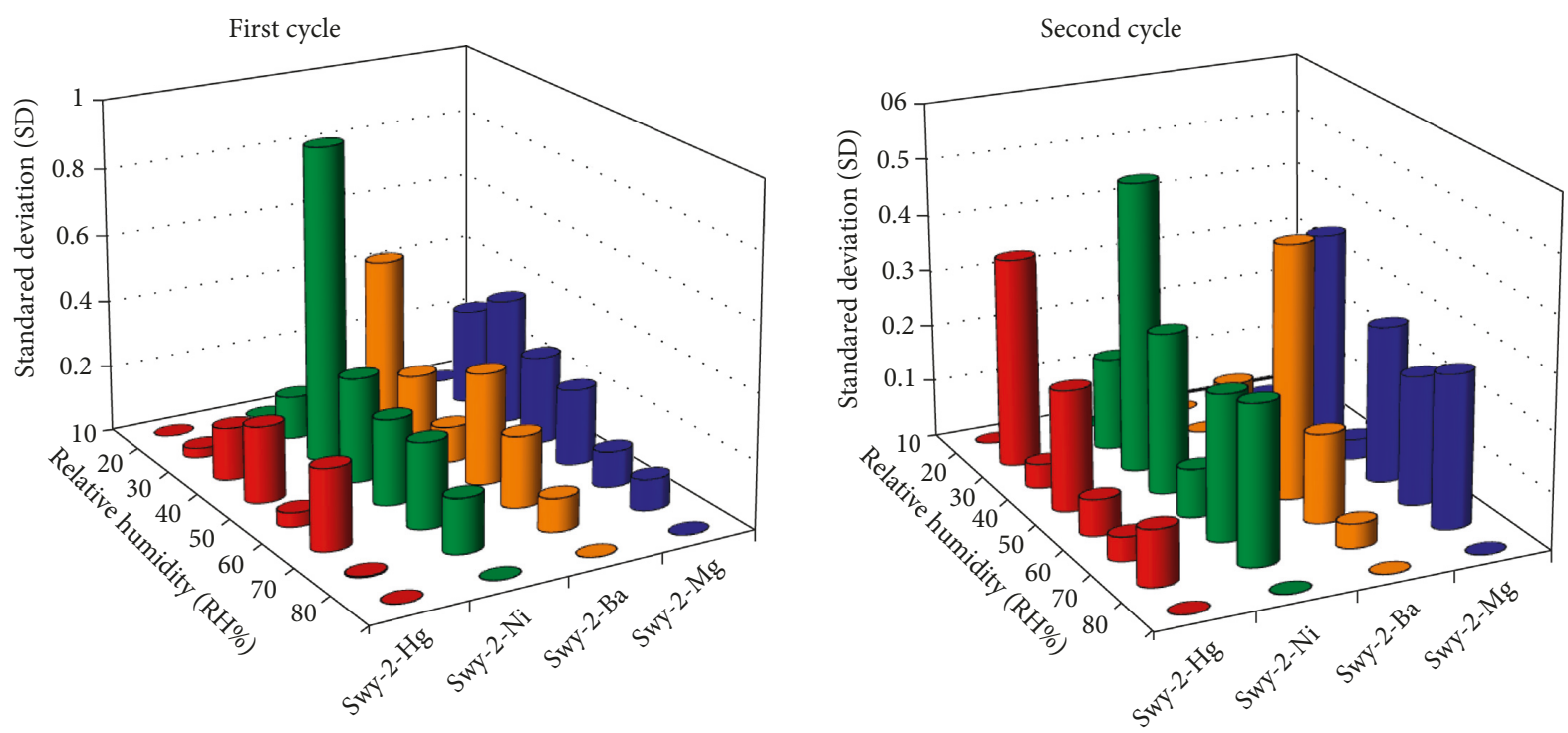

FIGURE 10: Stacked histogram of the hydration SD for the montmorillonite exchanged with divers cations during the hydrationdehydration cycle.

accompanied by more orderliness of systems and decrease in the water-content fluctuation.

(iv) The effect of the ionic potential parameter on the interlayer water retention mechanism, under controlled atmosphere (i.e, variable $\mathrm{RH}$ ), is not justified and cannot give a logical explanation on the progress of hydration behaviors of different complex.

\section{Data Availability}

No data were used to support this study.

\section{Conflicts of Interest}

The authors declare that they have no conflicts of interest.

\section{Acknowledgments}

The results presented are a part of the Ph.D. thesis of Marwa Ammar realized at the PMLNMH (UR05/13-01) Faculty of Science of Bizerte, Tunisia, cosupervised by Dr. Walid Oueslati and Prof. Abdesslem Ben Haj Amara. Marwa Ammar acknowledges Dr. W. Oueslati for the fruitful 
discussions about smectite hydration, her main contribution in the XRD modeling approach, and the proof reading of the manuscript.

\section{References}

[1] D. Charpentier, M. D. Buatier, E. Jacquot, A. Gaudin, and C. G. Wheat, "Conditions and mechanism for the formation of iron-rich Montmorillonite in deep sea sediments (Costa Rica margin): coupling high resolution mineralogical characterization and geochemical modeling," Geochimica et Cosmochimica Acta, vol. 75, no. 6, pp. 1397-1410, 2011.

[2] O. Karnland, S. Olsson, and U. Nilsson, "Mineralogy and sealing properties of various bentonites and smectite-rich clay materials," SKB internal report TR-06-30, 2006.

[3] R. L. Anderson, I. Ratcliffe, H. C. Greenwell, P. A. Williams, S. Cliffe, and P. V. Coveney, "Clay swelling-a challenge in the oilfield," Earth-Science Reviews, vol. 98, no. 3-4, pp. 201-216, 2010.

[4] N. G. Turan and O. Ozgonenel, "Study of montmorillonite clay for the removal of copper(II) by adsorption: full factorial design approach and cascade forward neural network," Scientific World Journal, vol. 2013, 342628, 11 pages, 2013.

[5] T. D. Pham, H. H. Nguyen, N. V. Nguyen et al., "Adsorptive removal of copper by using surfactant modified laterite soil," Journal of Chemistry, vol. 2017, Article ID 1986071, 10 pages, 2017.

[6] X. Gu, L. J. Evans, and S. J. Barabash, "Modeling the adsorption of $\mathrm{Cd}(\mathrm{II}), \mathrm{Cu}(\mathrm{II}), \mathrm{Ni}(\mathrm{II}), \mathrm{Pb}$ (II) and $\mathrm{Zn}$ (II) onto montmorillonite," Geochimica et Cosmochimica Acta, vol. 74, no. 20, pp. 5718-5728, 2010.

[7] K. L. Wasewar, P. Kumar, S. Chand, B. N. Padmini, and T. T. Teng, "Adsorption of cadmium ions from aqueous solution using granular activated carbon and activated clay," Clean: Soil, Air, Water, vol. 38, no. 7, pp. 649-656, 2010.

[8] M. M. Akafia, T. J. Reich, and C. M. Koretsky, "Assessing Cd, $\mathrm{Co}, \mathrm{Cu}, \mathrm{Ni}$, and $\mathrm{Pb}$ sorption on montmorillonite using surface complexation models," Applied Geochemistry, vol. 26, pp. S154-S157, 2011.

[9] B. Doua, V. Dupont, W. Panc, and B. Chenc, "Removal of aqueous toxic $\mathrm{Hg}$ (II) by synthesized $\mathrm{TiO} 2$ nanoparticles and TiO2/montmorillonite," Chemical Engineering Journal, vol. 166, no. 2, pp. 631-638, 2011.

[10] S. N. Rajurkar, N. A. Gokarn, and K. Dimya, "Adsorption of chromium(III), nickel(II), and copper(II) from aqueous solution by activated alumina," Clean: Soil, Air, Water, vol. 39, no. 8, pp. 767-773, 2011.

[11] J. Zhu, V. Cozzolino, M. Pigna, Q. Huang, A. G. Caporale, and A. Violante, "Sorption of $\mathrm{Cu}, \mathrm{Pb}$ and $\mathrm{Cr}$ on $\mathrm{Na}$ montmorillonite: competition and effect of major elements," Chemosphere, vol. 84, no. 4, pp. 484-489, 2011.

[12] J. L. Sutera, M. Sprik, and E. S. Boek, "Free energies of absorption of alkali ions onto beidellite and montmorillonite surfaces from constrained molecular dynamics simulations," Geochimica et Cosmochimica Acta, vol. 91, pp. 109-119, 2012.

[13] Y. Tachi and K. Yotsuji, "Diffusion and sorption of Cs+, Na+, I- and HTO in compacted sodium montmorillonite as a function of porewater salinity: Integrated sorption and diffusion model," Geochimica et Cosmochimica Acta, vol. 132, pp. 75-93, 2014.

[14] F.M. Huber, S. Heck, L. Truche et al., "Radionuclide desorption kinetics on synthetic $\mathrm{Zn} / \mathrm{Ni}$-labeled montmorillonite nanoparticles," Geochimica et Cosmochimica Acta, vol. 148, pp. 426-441, 2015.
[15] K. K. Norrfors, M. Bouby, S. Heck et al., "Montmorillonite colloids: I. Characterization and stability of dispersions with different size fractions," Applied Clay Science, vol. 114, pp. 179-189, 2015.

[16] Z. Y. Li, Z. W. Ma, T. J. Kuijp, Z. W. Yuan, and L. Huang, “A review of soil heavy metal pollution from mines in China: pollution and health risk assessment," Science of the Total Environment, vol. 468-469, pp. 843-853, 2014.

[17] A. E. Burakov, E. V. Galunin, I. V. Burakova et al., "Adsorption of heavy metals on conventional and nanostructured materials for wastewater treatment purposes: a review," Ecotoxicology and Environmental Safety, vol. 148, pp. 702-712, 2018.

[18] T. Nguyen, H. Ngo, W. Guo et al., "Applicability of agricultural waste and by-products for adsorptive removal of heavy metals from wastewater," Bioresource Technology, vol. 148, pp. 574-585, 2013.

[19] D. A. Glatstein and F. M. Francisca, "Influence of $\mathrm{pH}$ and ionic strength on $\mathrm{Cd}, \mathrm{Cu}$ and $\mathrm{Pb}$ removal from water by adsorption in Na-Bentonite," Applied Clay Science, vol. 118, pp. 61-67, 2015.

[20] B. Alyüz and S. Veli, "Kinetics and equilibrium studies for the removal of nickel and zinc from aqueous solutions by ion exchange resins," Journal of Hazardous Materials, vol. 167, no. 1-3, pp. 482-488, 2009.

[21] N. Malikova, A. Cadène, E. Dubois et al., "Water diffusion by quasi-elastic neutron scattering in a synthetic hectoritea model clay system," Journal of Physical Chemistry C, vol. 111, no. 47, pp. 17603-17611, 2007.

[22] B. Rotenberg, V. Marry, R. Vuilleumier, N. Malikova, C. Simon, and P. Turq, "Water and ions in clays: unraveling the interlayer/micropore exchange using molecular dynamics," Geochimica et Cosmochimica Acta, vol. 71, no. 21, pp. 5089-5101, 2007.

[23] E. Ferrage, B. Lanson, L. J. Michot, and J. L. Robert, "Hydration properties and interlayer organization of water and ions in synthetic $\mathrm{Na}$-smectite with tetrahedral layer charge. Part 1. Results from X-ray diffraction profile modeling," Journal of Physical Chemistry C, vol. 114, no. 10, pp. 45154526, 2010.

[24] A. Derkowski, V. A. Drits, and D. K. McCarty, "Rehydration of dehydrated-dehydroxylated smectite in a low water vapor environment," Mineralogical Society of America, vol. 97, no. 1, pp. 110-127, 2012.

[25] M. Fleury, E. Kohler, F. Norrant, S. Gautier, J. M'Hamdi, and L. Barre, "Characterization and quantification of water in smectites with low-field NMR," Journal of Physical Chemistry C, vol. 117, no. 9, pp. 4551-4560, 2013.

[26] F. Salles, J. M. Douillarda, O. Bildsteinb et al., "Driving force for the hydration of the swelling clays: case of montmorillonites saturated with alkaline-earth cations," Journal of Colloid and Interface Science, vol. 395, pp. 269-276, 2013.

[27] B. Dazas, B. Lanson, A. Delville et al., "Influence of tetrahedral layer charge on the organization of interlayer water and ions in synthetic Na-saturated smectites," Journal of Physical Chemistry C, vol. 119, no. 8, pp. 4158-4172, 2015.

[28] B. Lanson, S. Lantenois, P. Van Aken, A. Bauer, and A. Plançon, "Experimental investigation of smectite interaction with metal iron at $80^{\circ} \mathrm{C}$ : structural characterization of newly-formed Fe-rich phyllosilicates," American Mineralogist, vol. 97, no. 5-6, pp. 864-871, 2012.

[29] L. J. Michot, I. Bihannic, M. Pelletier, E. Rinnert, and J. L. Robert, "Hydration and swelling of synthetic Nasaponites: influence of layer charge," American Mineralogist, vol. 90, no. 1, pp. 166-172, 2005. 
[30] D. A. Laird, "Influence of layer charge on swelling of smectites," Applied Clay Science, vol. 34, no. 1-4, pp. 74-87, 2006.

[31] M. S. Karmous, H. Ben Rhaiem, J.-L. Robert, B. Lanson, and A. Ben Haj Amara, "Charge location effect on the hydration properties of synthetic saponite and hectorite saturated by $\mathrm{Na}$ +, Ca2+ cations: XRD investigation," Applied Clay Science, vol. 46, no. 1, pp. 43-50, 2009.

[32] K. U. Mohammad, "A review on the adsorption of heavy metals by clay minerals, with special focus on the past decade," Chemical Engineering Journal, vol. 308, pp. 438-462, 2017.

[33] V. Masindi and W. M. Gitari, "Simultaneous removal of metal species from acidic aqueous solutions using cryptocrystalline magnesite/bentonite clay composite: an experimental and modelling approach," Journal of Cleaner Production, vol. 112, pp. 1077-1085, 2016.

[34] G. M. Joziane, P. M. Murilo, K. Thirugnanasambandham et al., "Preparation and characterization of calcium treated bentonite clay and its application for the removal of lead and cadmium ions: adsorption and thermodynamic modeling," Process Safety and Environmental Protection, vol. 111, no. \#, pp. 244-252, 2017.

[35] M. V. Villar and A. Loret, "Influence of temperature on the hydro- mechanical behavior of a compacted bentonites," Applied Clay Science, vol. 26, no. 1-4, pp. 337-350, 2004.

[36] W. Oueslati, H. Ben Rhaiem, and A. Ben Haj Amara, "XRD investigations of hydrated homoionic montmorillonite saturated by several heavy metal cations," Desalination, vol. 271, no. 1-3, pp. 139-149, 2011.

[37] R. Chalghaf, W. Oueslati, M. Ammara, H. Ben Rhaiema, and A. Ben Haj Amarara, "Effect of temperature and $\mathrm{pH}$ value on cation exchange performance of natural clay for selective $\left(\mathrm{Cu}^{2+}\right.$, $\mathrm{Co}^{2+}$ ) removal: equilibrium, sorption and kinetics," Progress in Natural Science: Materials International, vol. 23, no. 1, pp. 23-35, 2013.

[38] B. Lanson, "Modelling of X-ray diffraction profiles: investigation of defective lamellar structure crystal chemistry," EMU Notes in Mineralogy, vol. 11, pp. 151-202, 2011.

[39] B. Lanson, "Crystal structure of mixed-layer minerals and their X-ray identification: new insights from X-ray diffraction profile modelling," Clay Science, vol. 12, no. 1, pp. 1-5, 2005.

[40] E. Ferrage, B. Lanson, N. Malikova, A. Planc, B. A. Sakharov, and V. A. Drits, "New insights on the distribution of interlayer water in bi-hydrated smectite from X-ray difraction profile modeling of 001 reflections," Chemistry of Materials, vol. 17, no. 13, pp. 3499-3512, 2005.

[41] V. A. Drits and C. Tchoubar, X-ray Diffraction by Disordered Lamellar Structures: Theory and Applications to Microdivided Silicates and Carbons, Springer-Verlag, Berlin, Germany, 1990.

[42] E. Ferrage, B. Lanson, B. A. Sakharov, and V. A. Drits, "Investigation of smectite hydration properties by modeling of X-ray diffraction profiles. Part 1. Montmorillonite hydration properties," American Mineralogist, vol. 90, no. 8-9, pp. 1358-1374, 2005b.

[43] E. Ferrage, C.A. Kirk, G. Cressey, and J. Cuadros, "Dehydration of Ca-montmorillonite at the crystal scale. Part 2. Mechanisms and kinetics," American Mineralogist, vol. 92, no. 7, pp. 1007-1017, 2007.

[44] E. Ferrage, B. A. Sakharov, L. J. Michot et al., "Hydration properties and interlayer organization of water and ions in synthetic Na smectite with tetrahedral layer charge. Part 2. Toward a precise coupling between molecular simulations and diffraction data," Journal of Physical Chemistry C, vol. 115, no. 5, pp. 1867-1881, 2011.

[45] R. Chalghaf, W. Oueslati, M. Ammar, H. Ben Rhaiem, and A. Ben Haj Amara, "Effect of an in situ hydrous strain on the ionic exchange process of dioctahedral smectite: case of solution containing $\left(\mathrm{Cu}^{2+}, \mathrm{Co}^{2+}\right)$ cations," Applied Surface Science, vol. 258, no. 22, pp. 9032-9040, 2012.

[46] W. Oueslati, H. Ben Rhaiem, and A. Ben Haj Amara, "Effect of relative humidity constraint on the metal exchanged montmorillonite performance: An XRD profile modeling approach," Applied Surface Science, vol. 261, pp. 396-404, 2012.

[47] W.F. Moll, "Baseline studies of the clay minerals society source clays: Geological origin," Clays and Clay Minerals, vol. 49, no. 5, pp. 374-380, 2001.

[48] A. Sari and M. Tuzen, "Cd(II) adsorption from aqueous solution by raw and modified kaolinite," Applied Clay Science, vol. 88-89, pp. 63-72, 2014.

[49] W. Oueslati, N. Chorfi, and M. Abdelwahed, "Effect of mechanical constraint on the hydration properties of $\mathrm{Na}$ montmorillonite: study under extreme relative humidity conditions," Powder Diffraction, vol. 32, no. S1, pp. S160S167, 2017.

[50] S. Lantenois, B. Lanson, F. Muller, A. Bauer, M. Jullien, and A. Plançon, "Experimental study of smectite interaction with metal iron at low temperature. 1. Smectite destabilization," Clays and Clay Minerals, vol. 53, no. 6, pp. 597-612, 2005.

[51] H. Ben Rhaiem, D. Tessier, and A. Ben Haj Amara, "Mineralogy of the $<2 \mathrm{~mm}$ fraction of three mixed-layer clays from southern and central Tunisia," Clay Minerals, vol. 35, no. 2, pp. 375-381, 2000.

[52] M. Ammar, W. Oueslati, H. Ben Rhaiem, and A. Ben Haj Amara, "Efect of the hydration sequence orientation on the structural properties of $\mathrm{Hg}$ exchanged montmorillonite: quantitative XRD analysis," Journal of Environmental Chemical Engineering, vol. 2, no. 3, pp. 1604-1611, 2014.

[53] M. Ammar, W. Oueslati, N. Chorfi, and H. B. Rhaiem, "Interlamellar space configuration under variable environmental conditions in the case of Ni-exchanged montmorillonite: quantitative XRD analysis," Journal of Nanomaterials, vol. 2014, Article ID 284612, 13 pages, 2014.

[54] W. Oueslati, M. Ammar, and N. Chorfi, "Quantitative XRD analysis of the structural changes of Ba-exchanged montmorillonite: effect of an in situ hydrous perturbation," Minerals, vol. 5, no. 3, pp. 507-526, 2015.

[55] G. Christidis and A. C. Dunham, "Compositional variations in smectites. Part II: alteration of acidic precursors-a case study from Milos Island, Greece," Clay Minerals, vol. 32, no. 2, pp. 255-273, 1997.

[56] C. I. Sainz Diaz, J. Cuadros, and A. Hernandez Laguna, "Analysis of cation distribuation in the octahedral sheet of dioctahedral 2:1 phyllosilicates by using inverse Monte Carlo methods," Physics and Chemistry of Minerals, vol. 28, pp. $445-454,2001$. 


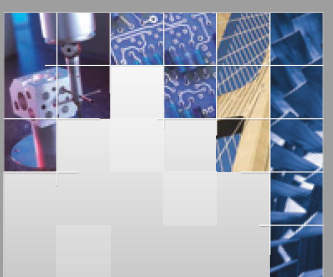

\section{Enfincering}
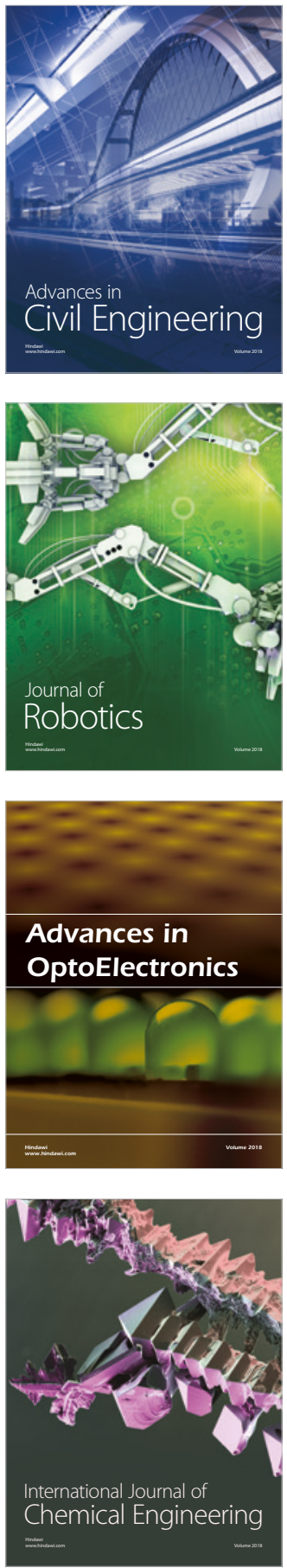

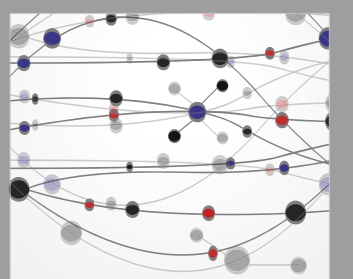

\section{Rotating \\ Machinery}

The Scientific World Journal

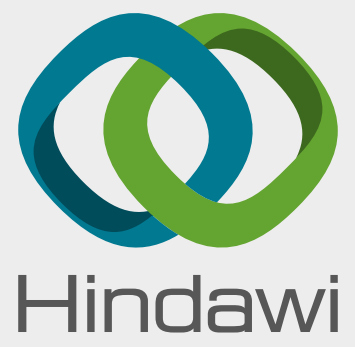

Submit your manuscripts at

www.hindawi.com
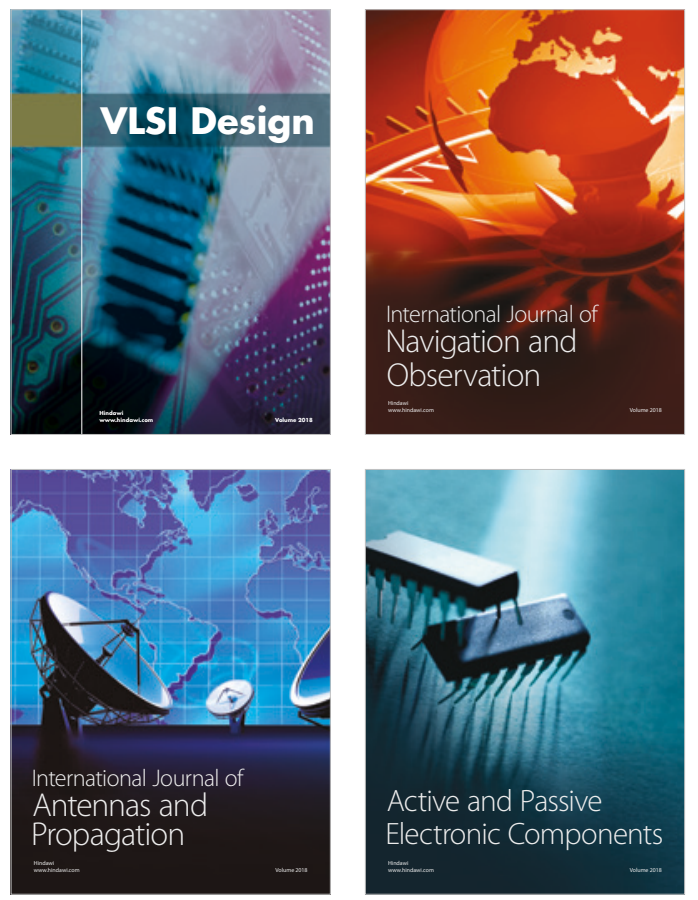
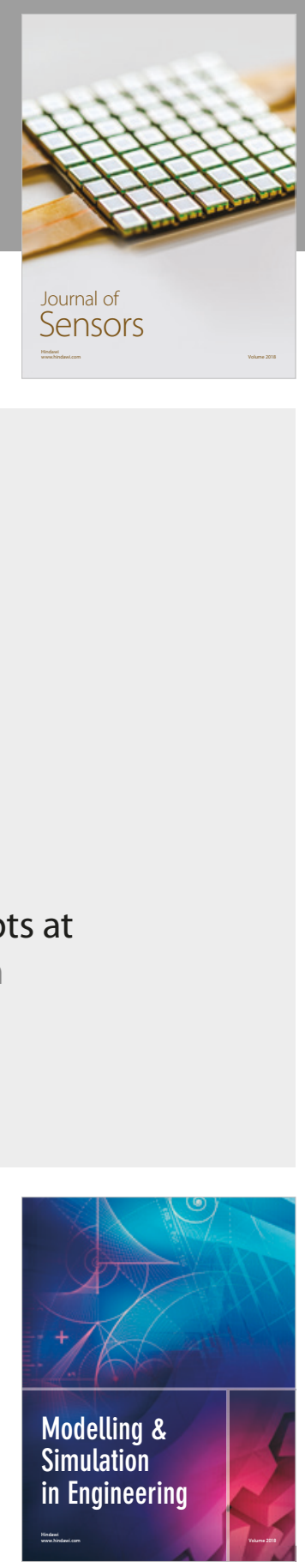

\section{Advances \\ Multimedia}
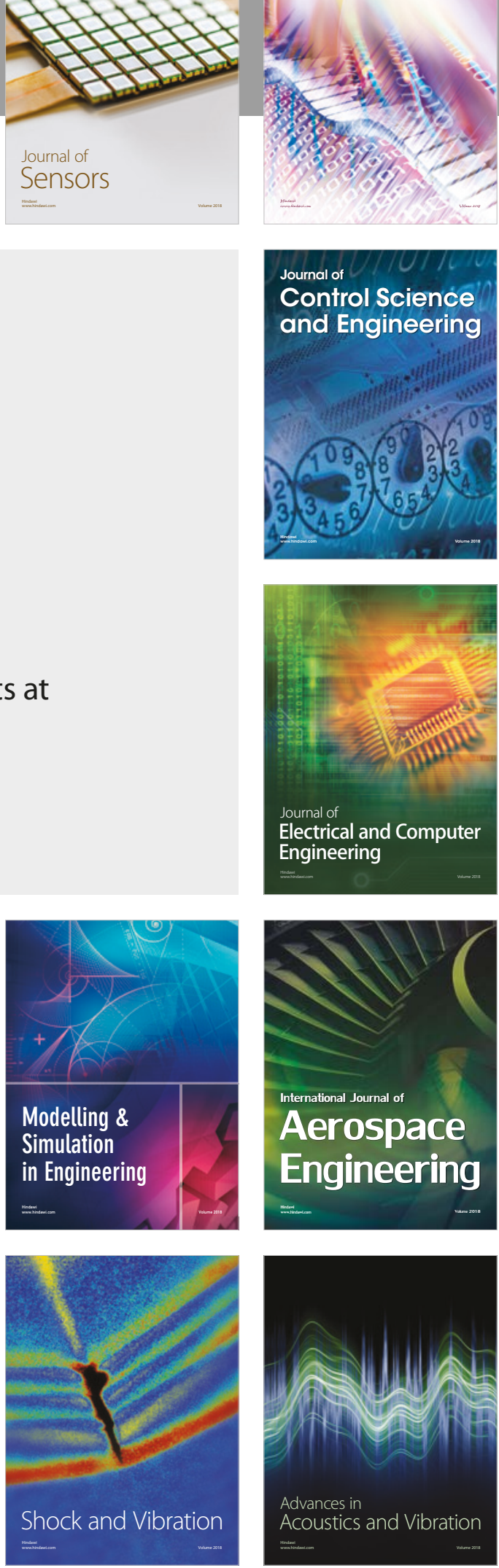